\title{
Análisis del retorno de la inversión en la gestión comercial de los supermercados en el Perú
}

\author{
Alfredo Zamudio Gutierrez ${ }^{1}$ \\ Escuela de Postgrado de la Universidad Peruana de Ciencias Aplicadas (UPC, Lima, Perú)
}

\section{RESUMEN}

Para el año 2008 se contaba con 121 supermercados en el Perú y a Diciembre 2012 se incrementó a 205 locales. Estas cifras muestran un pleno crecimiento de los supermercados. Es así que nace el presente estudio, analizar el retorno de la inversión en la gestión comercial de los supermercados en el Perú. Según Maximixe (2013) el Perú, a diferencia de otros países como Chile, Brasil y Ecuador presenta una participación de mercado de 15\%, mientras que los otros tres países presentan en promedio $60 \%$ del mercado moderno. El estudio analizará los supermercados de categoría económicos de medianas superficies, es decir de 1.500 a $2.500 \mathrm{~m}^{2}$ de superficie de venta, donde se manejan 20,000 productos aproximadamente, que son los supermercados más representativos y de mayor presencia en el Perú.

La investigación tiene como propósito, analizar el retorno de la inversión en la gestión comercial de los supermercados en el Perú utilizando métricas no financieras, para ello se evaluará previamente el análisis de la inversión con métricas financieras, las que servirán de base inicial o estructura para utilizar la nueva metodología propuesta, la cual será explicada en la sección de metodología. Por este motivo es importante conocer los parámetros financieros y no financieros del crecimiento.

\footnotetext{
${ }^{1}$ Director del Área Académica de Finanzas y candidato a Doctor en Administración y Dirección de Empresas, Universitat Politècnia de Catalunya. Correo: alfredo.zamudio@upc.edu.pe

Zamudio Gutierrez, A. (2015). Análisis del retorno de la inversión en la gestión comercial de los supermercados en el Perú. Sinergia e Innovación, 3(1), 134-192.

Fecha de recepción: 09/04/15

Fecha de aceptación: 30/04/15
} 


\title{
PALABRAS CLAVE
}

Retorno de la inversión; gestión comercial; retail; Perú; supermercados; canales formales; métricas financieras; métricas no financieras

\section{Analysis of the return on investment in sales management in supermarkets in} Peru

\begin{abstract}
By 2008, Peru had 121 supermarkets and by December 2012, the number increased to 205 . These numbers show booming supermarket growth. Thus, the current study analyzes the return on investment in sales management among supermarkets in Peru. According to Maximixe (2013), supermarkets in Peru have a 15\% market share while other countries like Chile, Brasil and Ecuador have a market share closer to $60 \%$. This study analyzes bargain, medium-sized supermarkets ( 1,500 to 2,500 square meters of sales floor) that sell approximately 20,000 products, which are the most representative and common supermarkets in Peru.
\end{abstract}

This research seeks to analyze the return on investment of sales management in supermarkets in Peru using non-financial metrics. To do so, we will use financial metrics to analyze the return on investment as a baseline or structure to use the new methodology proposed and explained in a later section. This makes understanding the financial and non-financial growth metrics important.

\section{KEYWORDS}

Return on investment; sales management; Peru; supermarkets; formal channels; financial metrics; non-financial metrics 


\section{Introducción}

La globalización ha transformado nuestra realidad y es un hecho irreversible. En ese contexto, las empresas deben orientarse a desarrollar ideas novedosas que contrarresten sus efectos negativos, y a aprovechar las oportunidades y se propongan nuevas formas de hacer más rentable a los negocios.

Durante los últimos 15 años, el sector supermercados en el Perú ha mostrado gran dinamismo, con una creciente expansión de cadenas de supermercados. Hoy tres grupos económicos manejan los supermercados en el Perú: Cencosud, que representa supermercados Wong y Metro; Interbank, que representa supermercados Plaza Vea y Vivanda, y Falabella, que representa supermercados Tottus. Para 2008, se contaba con 121 supermercados y, a diciembre 2012, se incrementó a 205. Estas cifras muestran un pleno crecimiento. Debido al bajo nivel de penetración que tiene nuestro país, existe un mercado potencial atractivo por desarrollar. Sin embargo, este crecimiento debe ir acompañado de una gestión comercial adecuada y un manejo del retorno de la inversión apropiado (Maximixe, 2013).

Así, nace el presente estudio, con el deseo de analizar el retorno de la inversión en la gestión comercial de los supermercados en el Perú. Según Maximixe (2013), a diferencia de países como Chile, Brasil y Ecuador, cuyo promedio es de $60 \%$ del mercado moderno, el Perú ofrece una participación de mercado de 15\%. El mercado tradicional domina aún el mercado peruano, con 85\% aproximadamente. Los consumidores prefieren todavía comprar en bodegas y puestos de mercado.

Dada la efervescencia de este sector y la gran oportunidad de mercado potencial que presenta el Perú, es de interés analizar el retorno de la inversión en la gestión comercial de los supermercados de los tres grupos económicos mencionados.

La investigación pretende analizar los factores que definen el retorno de la inversión en la gestión comercial de los supermercados en el Perú utilizando principalmente métricas no financieras. Para ello, se evaluará previamente el análisis de la inversión con métricas financieras, que servirán de base para utilizar la nueva metodología propuesta, la cual será explicada en el capítulo de metodología.

Usualmente se utilizan métricas financieras para determinar el retorno de la inversión. Las métricas financieras son instrumentos necesarios, pero solo explican lo que ha pasado y, por tanto, solo permiten una gestión comercial reactiva en lugar de una proactiva. Para gestionar por 
delante de la información financiera, se necesitan algo más que métricas financieras. Se necesitan métricas no financieras que puedan adelantar lo que más tarde reflejen las métricas financieras.

Para afrontar la investigación, es necesario conocer la historia de este tipo de negocios no solo a escala nacional sino a escala internacional, pues en su origen las fórmulas de grandes superficies fueron importadas principalmente de Estados Unidos, pioneros en estos establecimientos.

El sector supermercados es de fuerte crecimiento en el Perú y también en toda América Latina, que aporta una importante contribución al empleo, a los cambios de hábitos en la compra cotidiana, el ocio y otros productos (Equilibrium Clasificadora de Riesgo, 2013). Por ello, es necesario conocer los parámetros financieros y no financieros del desarrollo.

Hoy el Perú presenta una situación económica bastante sólida, que atrae a los inversionistas de otros países y de grandes compañías transnacionales. Así, a través de tratados de libre comercio (TLC) busca mejorar su relación comercial con Estados Unidos, China, Japón, Corea y miembros de la Unión Europea. Esta relación comercial le permitirá participar con mayor fuerza en un comercio global y promoverá el ingreso de nuevos competidores en el mercado de consumo masivo, como la anunciada participación de Wal-Mart (Equilibrium Clasificadora de Riesgo, 2013).

El estudio analizará los supermercados de la categoría económicos, de medianas superficies, es decir, de 1.500 a 2.500 metros cuadrados de superficie de venta, donde se manejan 20.000 productos aproximadamente. Es decir, los supermercados más representativos y de mayor presencia en el Perú.

\section{El Entorno de los Supermercados en el Perú}

\subsection{Historia y desarrollo de los supermercados en el Perú}

En las décadas de 1960 y 1970 aparecieron en Lima las primeras tiendas de supermercados: Monterrey, Tía, Galax, Scala Gigante, Maxi y Súper Market. Desde 1975 el sector expresó cierto dinamismo y debido a ello se inauguraron más locales en Lima y en algunas de las principales ciudades. Después la crisis económica, social y política que asoló al país a fines de la década de 1980 afectó severamente al sector y las cadenas fueron cerrando paulatinamente sus tiendas (Equilibrium Clasificadora de Riesgo, 2013).

No obstante, hubo otras razones que contribuyeron al declive del negocio: las cadenas habían estandarizado sus productos, precios y servicios dirigidos a los niveles socioeconómicos de mayor 
poder adquisitivo, estrategia inicialmente buena, pero no tomó en cuenta la incorporación de nuevos estratos y la evolución del comportamiento del consumidor, quien exigía cada vez mayor diferenciación y variedad de productos y servicios, factores que otras empresas nacientes supieron aprovechar, como el caso de Wong (Equilibrium Clasificadora de Riesgo, 2013).

El Grupo Supermercados Wong inició sus operaciones en 1983 con su primer supermercado en San Isidro. De 1983 a 1990 abrió cinco tiendas. En 1992 inauguró su primer hipermercado, Metro, en Chorrillos. En 1993 compró la cadena de tiendas Galax y Todos, y ese año inauguró cuatro supermercados y un hipermercado. En 2006 el Grupo Wong contaba con 41 tiendas. En diciembre de 2007 el Grupo Cencosud, de Chile, compró el 100\% de las acciones del Grupo Supermercados Wong en una operación valorada en US\$500 millones (Equilibrium Clasificadora de Riesgo, 2013).

Supermercado Peruanos S. A., competidor principal del Grupo Wong, ingreso al mercado peruano en 1993 con la denominación de Supermercados Santa Isabel, a través de una empresa de capitales chilenos que compró los supermercados Scala, Mass y Top Market y arrendó la cadena de supermercados San Jorge. Luego, en 1998, Santa Isabel fue adquirida por la multinacional holandesa Royal Ahold. En diciembre de 2003 Ahold decide retirarse del mercado sudamericano y vende el $100 \%$ de las acciones que mantenía en Santa Isabel al Grupo Interbank. Así, el 19 de abril de 2007, como parte de un proceso de reorganización, se transfirieron las participaciones de IFH Perú, Interseguro y Banco Internacional del Perú a IFR Retail Corp. La composición del accionariado fue $67,49 \%$ a favor de IFH Retail Corp. y el porcentaje restante a Compass Capital Partners Corp. Al cierre de 2006, la firma contaba con 40 locales (Equilibrium Clasificadora de Riesgo, 2013).

Supermercados Tottus, del Grupo Saga Falabella (filial de la chilena Falabella), ingresó en noviembre de 2002, en el Centro Comercial Mega Plaza (Independencia). En noviembre de 2003 inauguró su segundo hipermercado, esta vez en San Isidro. En octubre de 2004 abrió su tercer local, ubicado en San Miguel, con Sodimac, y en el segundo trimestre de 2006 inauguró su cuarto local, en el Centro Comercial Plaza Atocongo. La diferencia entre supermercados e hipermercados está en el mayor abanico de productos y marcas. Al no contar con espacio, los supermercados ofrecen básicamente abarrotes y bienes de consumo no duraderos, mientras que los hipermercados incluyen productos durables en mayor proporción desde electrodomésticos hasta motos, (Equilibrium Clasificadora de Riesgo, 2013). 
La incursión de Saga Falabella en el negocio de supermercados bajo la marca Tottus y el dinamismo expansivo del sector se sustenta en la oportunidad que representa la reducida tasa de penetración que tienen los supermercados en el Perú del total facturado por comercio minorista (Equilibrium Clasificadora de Riesgo, 2013).

Figura 1 Desarrollo de los supermercados en el Perú

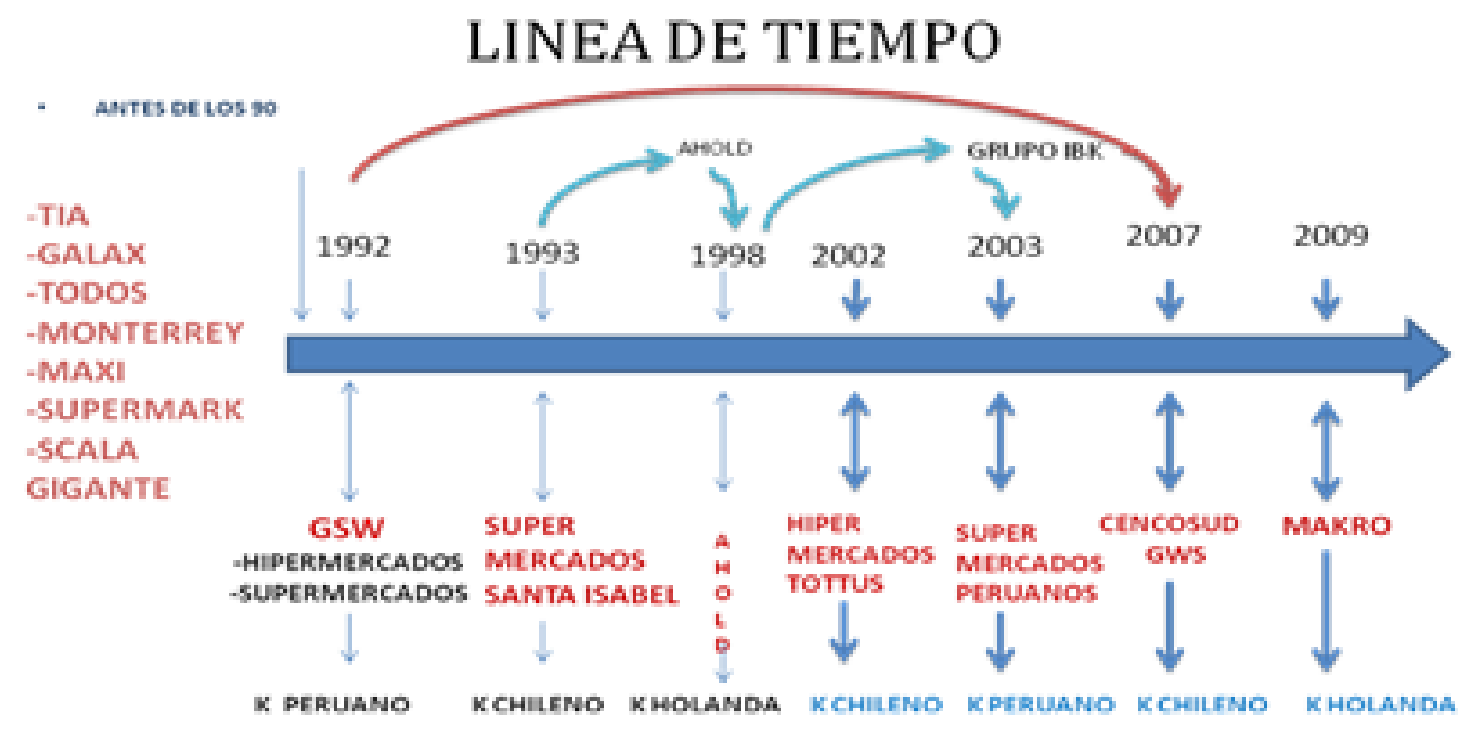

Elaboración propia en base a Equilibrium Clasificadora de Riesgo, 2013

Los tres operadores más importantes cuentan con 237 supermercados en el Perú: 96 Cencosud, 101 Interbank y 40 Falabella. La figura 1 muestra el desarrollo de los supermercados en el Perú (Equilibrium Clasificadora de Riesgo, 2013).

\subsection{Realidad de los supermercados en el Perú y en el mundo}

Un supermercado es un establecimiento comercial urbano que vende bienes de consumo en sistema de autoservicio, entre los que se encuentran alimentos, ropa, artículos de higiene, perfumería y limpieza. Estas tiendas pueden ser parte de una cadena, generalmente en forma de franquicia, que puede tener más sedes en la misma ciudad o país. Los supermercados generalmente ofrecen productos a bajo precio. Para generar beneficios, los supermercados intentan contrarrestar el bajo margen de beneficio con un alto volumen de ventas.

Los clientes que entran en un supermercado suelen recorren las instalaciones con un carrito o cesta, en el cual van guardando los productos que desean adquirir. Los productos se distribuyen 
por secciones: ultramarinos, alimentos frescos, alimentos congelados, bebidas, etcétera. Estas a su vez se organizan en pasillos clasificados por su naturaleza (galletas, cereales, frutas, carnes, etcétera). El cliente realiza el pago en cajas que se encuentran situadas en las salidas del establecimiento.

La distribución de secciones es muy similar en todos los supermercados estudiados. La intención es que el cliente describa el recorrido más amplio posible, por lo que los productos de primera necesidad se colocan en diferentes puntos del mismo y, generalmente, alejados de la entrada: carne, pescado, frutas y legumbres, juguetería, pan, leche, agua, etcétera.

Los muebles con estantes donde se exhiben los productos se denominan góndolas y su lateral, cabecera de góndola. Por su parte, los productos congelados y lácteos se exponen en arcones frigoríficos. La parte del mercadeo que se ocupa de las técnicas optimización de venta de productos en una superficie de autoservicio se denomina merchandising.

A escala global, existe un supermercado que lidera el mercado minorista: la cadena Wal-Mart Stores, Inc. Wal-Mart es una compañía estadounidense cuyo concepto de negocio es la tienda de autoservicio de bajo precio y alto volumen. Wal-Mart posee más de 7.400 tiendas y más de dos millones de empleados en el mundo. En el último año, su nivel de ventas superó US\$400.000 millones (Equilibrium Clasificadora de Riesgo, 2013).

Maximixe (2013) indica que Chile es la capital de los supermercados en Sudamérica. Según un análisis del Índice de Desarrollo Global de Supermercados de A. T. Kearney realizado por Maximixe (2013), Chile se encuentra en el octavo lugar de desarrollo del retail del mundo, pues en los primeros lugares están Vietnam, India, Rusia y China. Este índice clasifica a los países en función de 25 variables macroeconómicas (inflación y PBI entre las más importantes) y de mercado (precio, participación de mercado, volumen de ventas). La figura 2 muestra el Índice de Desarrollo Global de Supermercados a diciembre de 2013. 
Figura 2 Índice de desarrollo global de supermercados

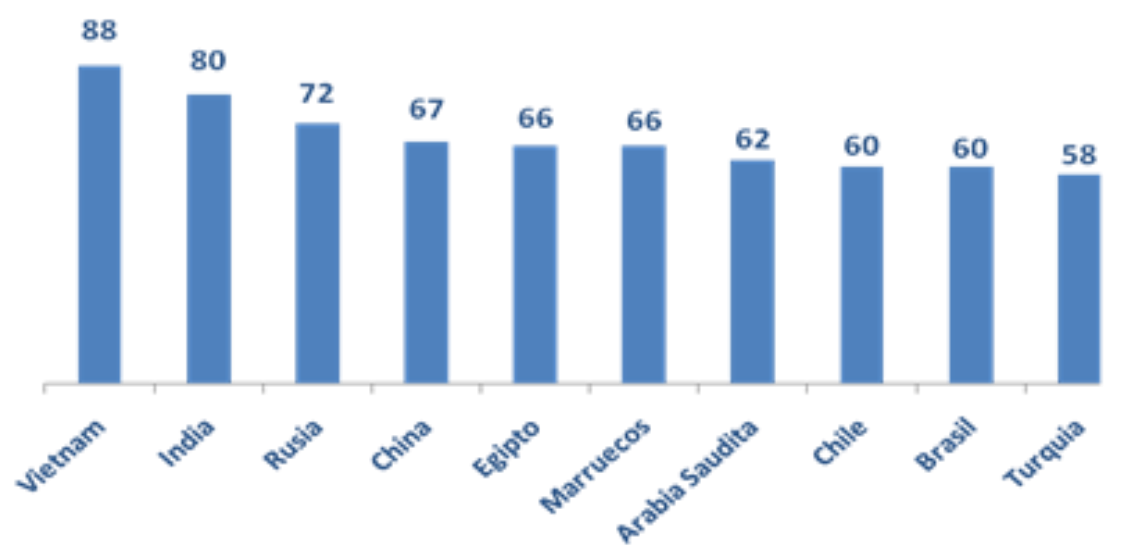

Fuente: Maximixe, 2013

En América Latina, las empresas chilenas incursionan en Argentina, Brasil, Colombia y el Perú, donde encuentran economías con crecimiento sostenido, buen manejo macroeconómico y baja penetración de este tipo de negocio (Maximixe, 2013).

Hoy, el Perú es el país con menor penetración de supermercados en toda la región, con 15\%, mientras que Chile presenta una penetración de mercado de casi $60 \%$. Se aprecia que el mercado tradicional es el principal medio de consumo en el Perú y algunos países de la región. La figura 3 muestra la penetración de los supermercados en América Latina (Maximixe, 2013).

El 85\% del comercio minorista nacional se concentra en canales tradicionales como bodegas, mientras que el $15 \%$ se concentra en supermercados. Si bien los supermercados se han expandido, dado el continuo crecimiento de la economía, en el mercado interno las bodegas de esquina siguen siendo el lugar preferido de los consumidores para adquirir productos de diferente tipo (Equilibrium Clasificadora de Riesgo, 2013). 
Figura 3 Penetración de los supermercados a América Latina

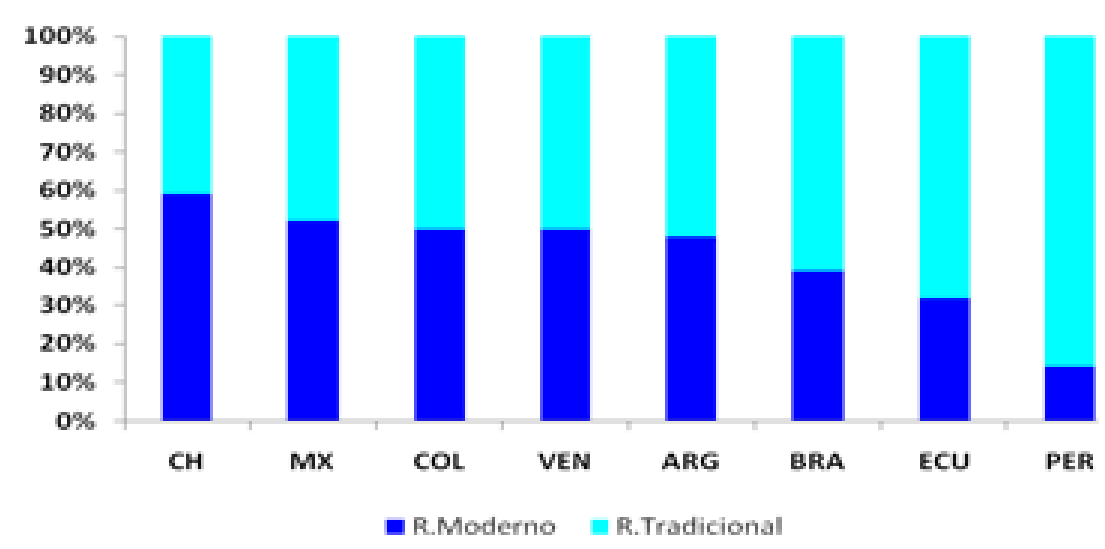

Fuente: Elaboración propia en base a Equilibrium Clasificadora de Riesgo, 2013.

Los canales tradicionales no solo se restringen a las bodegas de esquina, sino a otros establecimientos como casas ventas, puestos de mercado, minimercados, ferreterías, quioscos y bares. En 2013, Maximixe estimó que en 2014 Lima tendría 95.000 bodegas, 14.000 casas ventas, 12.000 puestos de mercado y 9.000 quioscos.

El número de locales de los supermercados en el Perú se muestran en la figura 4.

Figura 4 Número de locales de supermercado 2000-2013

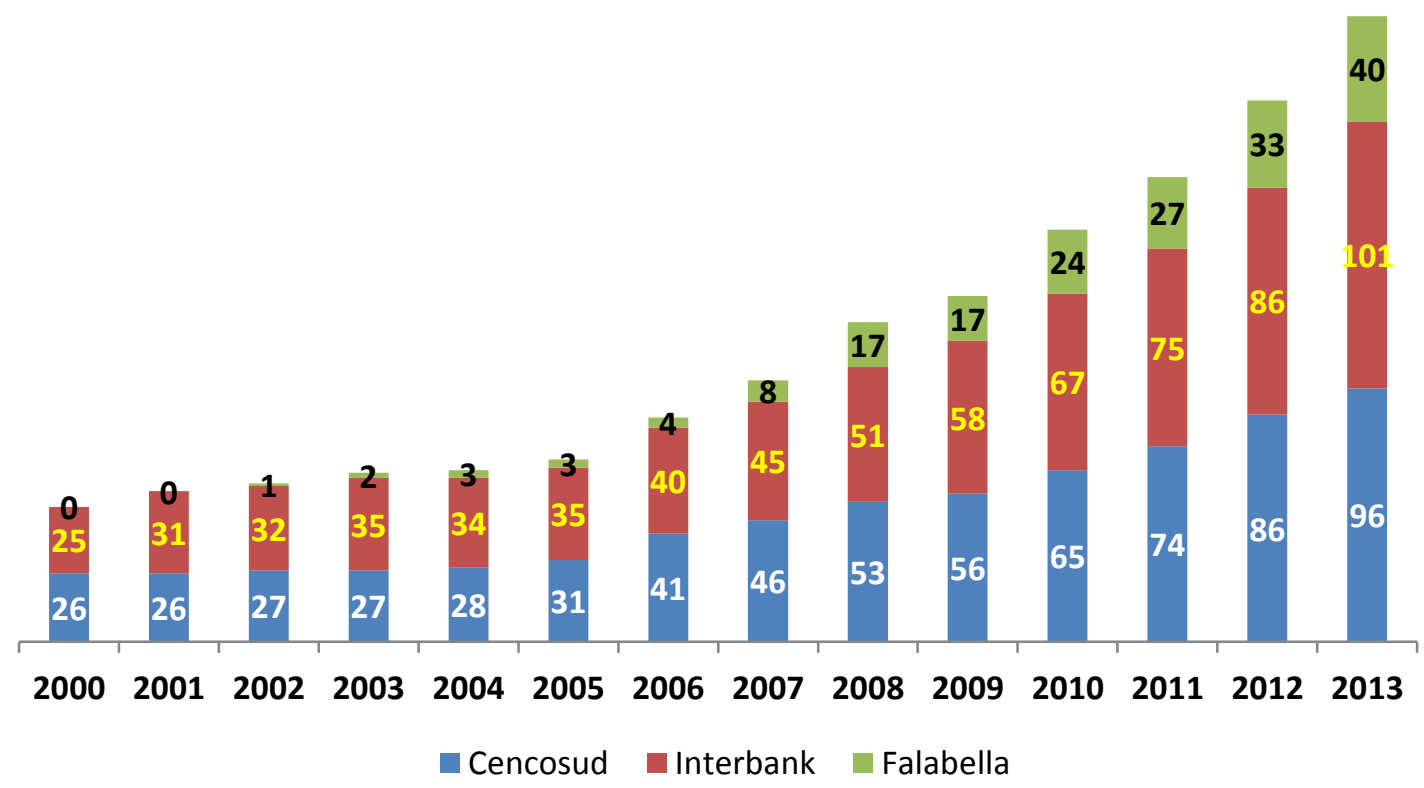

Fuente: Equilibrium Clasificadora de Riesgo, 2013 


\section{Planteamiento del Problema}

Los inversionistas tratan de recuperar su inversión en un tiempo adecuado. Las clásicas formas de medir el retorno de la inversión son: ROA (return on assets), ROE (return on equity) y ROI (return on investment), que no consideran al cliente como valor fundamental del negocio. Además, el retorno de la inversión es medido a través de métricas financieras, las cuales se centran en lo que ha pasado y, por tanto, solo permiten una gestión reactiva en lugar de una proactiva.

Para gestionar la información financiera, se necesita algo más que métricas financieras. Se requiere métricas no financieras que puedan adelantar lo que más tarde reflejen las métricas financieras. Es decir, los inversionistas de los diferentes sectores de la economía peruana y, en particular, el sector supermercados utilizan métricas financieras para evaluar su gestión comercial, dejando la oportunidad de desarrollar una gestión comercial proactiva a través de métricas no financieras.

Las métricas no financieras tienen dos ventajas fundamentales frente a las métricas financieras: permiten medir el retorno de la inversión a través del valor del cliente en la gestión comercial y desarrollar una gestión comercial proactiva. Entre las métricas no financieras más importantes y que propondré en este estudio para mejorar el retorno de la inversión tenemos las métricas del mercado, las métricas del cliente y las métricas del supermercado.

Considerando el fuerte avance de los supermercados en el Perú en los últimos años, calcular el retorno de la inversión ha tomado mucha relevancia. El retorno de la inversión de los supermercados es medido a través de métricas financieras, las cuales se centran en lo que ha pasado y, por tanto, solo permiten una gestión reactiva en lugar de una proactiva. Así, surge la necesidad de utilizar métrica no financieras para analizar el retorno de la inversión en los supermercados en el Perú.

Por ello, en este proyecto el desafío es responder a cuatro preguntas:

- ¿Cuál es el retorno de la inversión comercial de los supermercados en el Perú utilizando métricas no financieras de la gestión comercial?

- ¿Cuál es el retorno de la inversión comercial de los supermercados en el Perú utilizando métricas no financieras del mercado?

- ¿Cuál es el retorno de la inversión comercial de los supermercados en el Perú utilizando métricas no financieras del cliente? 
- ¿Cuál es el retorno de la inversión comercial de los supermercados en el Perú utilizando métricas no financieras del supermercado?

\section{Objetivos de Investigación}

El estudio determinó las metodologías para la estimación del retorno de la inversión comercial en el marco de los modelos financieros empresariales y sociales, propone un modelo que explique el comportamiento de este retorno en función de métricas no financieras de la gestión comercial. Para ello, y en concordancia con las preguntas de investigación, se comprometen los siguientes objetivos:

1. Estudiar las metodologías para calcular el retorno de la inversión en los supermercados, para proponer un nuevo modelo de estimación con alto valor agregado en la precisión de sus resultados.

2. Calcular el retorno de la inversión comercial realizada para cada supermercado, utilizando las métricas no financieras: métricas del mercado, del cliente y del supermercado.

3. Generar un marco de reflexión en cuanto a la aportación de la propuesta del modelo de análisis de retorno de la inversión comercial utilizando las métricas no financieras, el cual provee una visión estratégica del negocio.

\section{Marco Teórico Sobre el Retorno de la Inversión}

\subsection{Medición del retorno de la inversión de los supermercados en el Perú}

Las principales métricas financieras que se utilizan para medir el retorno de la inversión en el sector supermercados en el Perú son la utilidad operativa de corto plazo o Ebitda y el retorno de la inversión o ROI.

Utilidad operativa de corto plazo o Ebitda (earnings before interest, taxes, depreciation and amortization): Es el resultado de una empresa antes de intereses, impuestos, cargos diferidos y amortizaciones. Es un indicador que se mide exactamente como se indica, en el cual todos los intereses, impuestos, depreciación y amortización de las entradas en la cuenta de resultados se invierten fuera de la línea de fondo beneficio neto. Es considerado una métrica de rentabilidad que permite la aproximación al valor de una empresa y pretende medir los ingresos de efectivo sin la contabilidad de ejercicio, la cancelación de impuestos efectos de la competencia y la cancelación 
de los efectos de las diferentes estructuras de capital. Ebitda difiere del flujo de caja operativo, en un estado de flujo de efectivo principalmente por la exclusión de los pagos de impuestos o de interés, así como cambios en el capital de trabajo y también difiere de flujo de efectivo libre, porque excluye a las necesidades de efectivo para la sustitución de los bienes de capital.

Retorno de la inversión o ROI (return on investment): Es la razón financiera que compara la utilidad obtenida en relación con la inversión realizada. Es decir, representa la fórmula para analizar el retorno que la empresa tiene desde el punto de vista financiero. Para su cálculo, en el numerador se pueden admitir diferentes definiciones de beneficios, como el beneficio neto después de impuestos, el BAI (antes de impuestos) o el BAll (antes de intereses e impuestos, mientras que en el denominador se debe indicar los medios para obtener dicho beneficio).

\subsection{Nuevas métricas no financieras y el retorno de la inversión}

La medición del retorno de la inversión se realiza mediante el uso de las métricas financieras. Sin embargo, estas son instrumentos limitados, porque solo explican lo que ha pasado en la empresa, por ello permiten una gestión reactiva en lugar de una proactiva. Las métricas no financieras permiten evaluar la gestión comercial de manera proactiva y se anticipan a los resultados de la información financiera:

Satisfacción de los clientes: Consigue que a medio y largo plazos, la rentabilidad aumente, pero se debe asumir y entender que la satisfacción de los clientes va muy por delante de la rentabilidad y que no es un indicador puramente financiero.

En función de cómo este enfocado el plan de mercadeo, los objetivos financieros variarán. El enfoque del plan de mercadeo, además, será función de la estrategia del mercadeo. No es lo mismo una estrategia de mercadeo, que tenga una cartera de productos donde predominen los productos vaca o donde predominen los productos perro.

Las métricas no financieras pueden ayudar a descubrir problemas de índole comercial y de mercadeo.

Ventas insuficientes para los costes soportados: Descubre productos obsoletos o con ventas por debajo de su potencial esperado y presupuestado. Se fija en líneas o categorías de productos mal estructuradas o mal diversificadas, en el éxito o fracaso del lanzamiento de productos, en el nivel de precios de productos (que no sean muy elevados o bajos para su posicionamiento), en el nivel de conocimiento de la competencia, en los costes laborales del área de mercadeo, en el nivel de satisfacción del cliente, en la eficacia de las acciones de comunicación. 
Cada organización y cada profesional deben seleccionar las métricas que crea que son convenientes para monitorizar su actividad. Hay que recordar que medir por medir, además de ser caro, es inconsistente e ineficiente. La estrategia no la implanta el director general ni el director de mercadeo, sino todos quienes integran la organización. En nuestro caso, la organización del mercadeo.

Hay que considerar que en grandes empresas con gamas de productos amplias, diversidad de marcas y grandes territorios que cubrir, puede darse un plan general de mercadeo, un plan de mercadeo por mercados, un plan de mercadeo por líneas de productos, un plan específico por producto, un plan por divisiones territoriales, etcétera. Todo debe funcionar de forma sincronizada y eficiente, lo que implica tener que emplear métricas. Por el contrario, en una pyme, el propio plan de mercadeo, con una docena de métricas claves definidas, puede ser sustitutivo de una planificación estratégica más completa y compleja.

La selección de objetivos claves en el plan de mercadeo aporta una metodología que ayuda a elegir métricas y permite el diseño de un cuadro de mando que tenga en cuenta tanto el corto, el medio y el largo plazos.

Para Alejandro Domínguez Doncel y Gemma Muñoz Vera (2010), las métricas por definir y seleccionar dependerán de las estrategias y programas definidos en el plan de mercadeo. Lo ideal es identificar las posibles métricas a medida que se desarrolla el plan de mercadeo. Esto ayuda también a determinar qué métricas son responsabilidad de cada persona que elabora el plan de mercadeo.

Según estos especialistas, todas las métricas se deben definir en tres planos: el estratégico, el táctico y el operativo. El objetivo de utilizar este sistema es utilizar métricas concretas que también se utilicen en el nivel operativo, lo que permitirá ir corrigiendo y adelantando posibles desviaciones.

El corazón del mercadeo es la diferenciación. Si todas las empresas utilizarán las mismas métricas, fracasarían. Las métricas deben desarrollarse en función de las estrategias por seguir. Existen, de todas formas, métricas que deben ser de uso común, como la cuota de mercado o cuota cliente, necesaria para establecer comparaciones con empresas del mismo sector.

La excesiva simplificación es peligrosa, pues utilizar métricas de forma mecánica va en contra de su propósito. Son las preguntas del tipo por qué los consumidores nos compran y nos deberían comprar más, o no nos compran, las que deben arrancar el proceso de definición y desarrollo de 
las métricas. Un sentido aproximado de lo esencial es más importante que un cálculo preciso de lo irrelevante. Las métricas deben de formar parte de la cadena causa efecto.

Las perspectivas de las diferentes métricas deben estar relacionadas. Es fácil caer en la tentación de medir lo irrelevante por dos motivos, porque siempre se ha hecho así y porque resulta sencillo de medir (por eso, quizá se haya medido siempre).

No importa si no se puede medir de forma inmediata por falta de recursos o información. Es bueno comenzar a tener conciencia de las necesidades para cubrirlas. Se debe medir para conocer de dónde está saliendo el dinero que hace que la compañía funcione. El autocontrol por parte de la dirección es la mejor receta para hacer que funcione un sistema de métricas. Utilizarlas para su propia información y para comunicar y motivar a la organización a actuar de la misma forma. La experiencia dice que usar las métricas como simple sistema de control y recompensa es una pésima decisión.

Llegan a ser más importantes las métricas que los propios negocios, y desde el primer momento los distorsionan. Deben ser creíbles. Si se sospecha que la dirección puede estar manipulándolas, pierden la credibilidad y la parte de gestión ligada a ellas se desintegra. Los incentivos de la dirección deben recompensar el rendimiento individual. Las métricas pueden reflejar el rendimiento de toda la empresa. Si se utilizan las métricas solo como sistema de control, desmotivarán y proporcionarán rechazo.

\subsection{Métricas del mercado}

Las métricas del mercado se asocian al comportamiento de las categorías de la matriz BCG. La matriz BCG fue desarrollada por The Boston Consulting Group, firma estadounidense de consultoría de gestión estratégica, para analizar el rendimiento de los productos en función a la inversión realizada en ellos. La matriz mide el rendimiento del producto por el crecimiento y su cuota de mercado. Sirve fundamentalmente para analizar el atractivo del mercado (tasa de crecimiento) y la cuota de mercado, como medida de competitividad. La matriz desarrolla cuatro cuadrantes, que definen cada uno cuatro situaciones: productos estrella, interrogantes, vacas o perros. 
Figura 5 Matríz BCG (Boston Consulting Group)

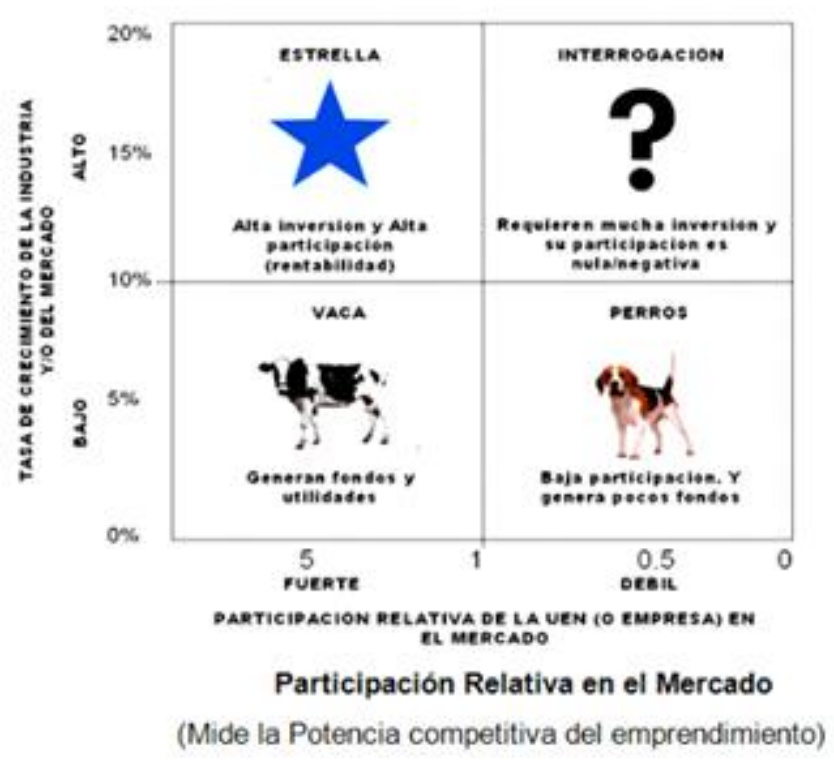

Fuente: adaptada de Stanton, Etzel \& Walker, 1994, p. 611

Además hay dos variables muy importantes para tomar decisiones estratégicas. Estas son:

Indicador de la cuota del mercado

La cuota de mercado es el porcentaje de mercado, definida en términos de unidades o de ingresos, de un producto específico. Este cálculo permite conocer qué cantidad de torta de mercado tiene la compañía y establecer previsiones de crecimiento. Permite también saber si estamos robando mercado a la competencia o si la competencia nos lo está robando.

\section{Indicador de la penetración del mercado}

Domínguez Doncel y Muñoz Vera (2010) señalan que la estrategia de penetración en el mercado consiste en desarrollar el negocio incrementando la participación de la empresa en los mercados en los que opera con los productos actuales. Esta estrategia se puede realizar orientando a que los clientes compren más productos o servicios (por ejemplo, desarrollando más servicios), atrayendo a los clientes de la competencia (bajando precios) o atrayendo a clientes potenciales (con promociones). Esta es, por tanto, una estrategia de crecimiento con reducido riesgo.

En resumen, la penetración de mercado se refiere a lo que podemos hacer para incrementar las ventas con los clientes que tenemos a través de los productos que poseemos actualmente. 


\subsection{Métricas del cliente}

Existen tres indicadores para evaluar clientes: la eficiencia, la eficacia y el retorno de la inversión (ROI). Estas tres métricas permiten reconocer que debe hacer para lograr conseguir o conservar clientes. Dependiendo del tipo de mercado en el que opera la empresa:

- En consumo: Se puede hacer por segmentos de cliente, debido a que no se puede identificar a cliente por cliente.

- En empresas industriales o de servicios: Se puede hacer por cliente, pues se tienen carteras de clientes mucho más reducidas.

Veremos ahora dos indicadores con los conceptos extraído de Domínguez Doncel y Muñoz Vera (2010).

\section{Indicador de la rentabilidad del cliente}

Mide el beneficio neto de un cliente o un segmento después de descontar los gastos asociados al mantenimiento de ese mercado o cliente. Los sistemas de costeo basados en las actividades ( $A B C$ costing) permiten medir la rentabilidad del cliente, el segmento o la categoría.

Tener éxito en los índices centrales del cliente (cuota, retención, incremento y satisfacción) no garantiza la rentabilidad del cliente. No todas las demandas de los clientes se pueden satisfacer, pues pueden ser demasiado caras para la empresa, obligándola a incrementar sus precios si es que el cliente o conjunto de clientes interesa. Puede resultar conveniente utilizar la segmentación $A B C$ para distinguir clientes.

Este tipo de segmentación revelará qué clientes no son rentables, pero habrá que tener en cuenta si son clientes nuevos por explotar o no, y si tienen potencial de crecimiento. Los antiguos clientes no rentables es posible que necesiten un plan para reactivarlos. También es posible que exista algún cliente que, no siendo rentable económicamente, convenga conservar por los beneficios que puede aportar a la imagen de la compañía.

\section{Indicador del valor del cliente}

El valor del cliente a largo plazo es una forma de medir el valor presente de los flujos de caja, atribuidos al patrón de consumo de un determinado cliente en el sector supermercados. Permite saber cuánto dinero puede llegar a aportar un determinado cliente en el futuro, si continúa con las mismas pautas de compra como hasta ahora. El sector supermercados es una actividad en la que se obtiene rápidamente la respuesta a las acciones (por ejemplo, en poco tiempo se sabe si una 
determinada presentación funciona o no). Ello conlleva el riesgo de practicar la profesión de forma cortoplacista.

Probablemente una de las métricas más comunes en los supermercados, sea cual sea el sector o el país, es el importe del tique medio, es decir, el promedio de las transacciones. Sin embargo, todavía no todos los directivos saben de memoria tal indicador. Y, por supuesto, también todos conocen las ventas del periodo, así como la facturación en relación con la misma época del año anterior, y la desviación con el presupuesto.

Todos estos indicadores tienen la ventaja de que son muy fáciles de obtener y de usar, pero tienen un inconveniente: se ve el negocio como una secuencia de fotos en lugar de dinámicamente, como una película. En la mayor parte de los supermercados, se busca no solo que una persona venga y compre una vez, sino que se convierta en cliente asiduo, incluso en fan. Y las métricas habituales no tienen en su ADN este enfoque de largo recorrido.

Kotler (1974, p. 20-29) definió la probabilidad de tener un cliente a largo plazo como el valor presente del beneficio futuro esperado a lo largo de un horizonte temporal de transacciones con el cliente.

\subsection{Métricas del supermercado}

Lo que buscan las métricas del supermercado es evaluar el comportamiento de la gestión logística y comercial del negocio. Para ello, se analizarán diversas métricas, entre las que cabe resaltar métricas como rotación de existencias, ciclo operativo, ciclo de conversión de efectivo, entre otras.

\section{Rotación de inventarios o existencias}

\section{Ventas a precio de coste}

Son las unidades vendidas durante el periodo. Pueden expresarse en unidades físicas o en unidades monetarias. En este último caso, la cifra debe reflejar el coste de las ventas (o las ventas a precio de coste), no los ingresos por ventas, pues distorsionaría el resultado.

\section{Existencias medias}

Son las unidades almacenadas por término medio durante el periodo. Igualmente pueden expresarse en unidades físicas o en unidades monetarias, a su valor en el almacén.

Las dos cifras deben expresarse en la misma unidad.

Fórmula para determinar la rotación de inventarios 
La rotación de inventarios se determina dividiendo el coste de las mercancías vendidas en la etapa entre el promedio de inventarios durante el periodo (coste mercancías vendidas/promedio inventarios) $=\mathrm{N}$ veces.

\section{Ciclo operativo y ciclo de efectivo}

Es el periodo de tiempo requerido para adquirir inventarios, venderlos y cobrarlos. El ciclo operativo tiene dos partes. La primera es el tiempo necesario para adquirir y vender los inventarios. Se llama etapa de inventarios (PIN). La segunda es la etapa requerida para cobrar las ventas. Se denomina periodo de cuentas por cobrar (PCC).

El ciclo de efectivo es el número de días que transcurren hasta que ingresa el importe de efectivo de una venta, medido desde el momento que se pagaron estos productos del inventario.

\section{Ciclo de conversión de efectivo}

Es una herramienta muy común, utilizada por los funcionarios de negocios de las entidades crediticias, para evaluar las necesidades de liquidez de los potenciales prestatarios. Es el ciclo de conversión de efectivo (CCE) del negocio.

El ciclo de conversión de efectivo del negocio se compone de tres elementos:

- Días promedio de inventario (DPI).

- Días promedio de cobranzas (DPC).

- Días promedio de pago (DPP).

Interpretación de DPI, DPC y DPP: Si los días promedio de inventario (DPI) y los días promedio de cobranza (DPC) superan los días promedio de pago (DPP), la empresa tendrá ciclo de conversión de efectivo (CCE). Es decir, si los días de crédito que se recibe de proveedores (DPP) son insuficientes para financiar el crédito que se otorga a clientes (DPC) y los días que se mantiene la mercadería en almacenes (DPI), la empresa tendrá ciclo de conversión de efectivo (CCE). Si es así, requerirá de préstamo para capital de trabajo, a menos que financie sus necesidades con recursos propios, es decir, con patrimonio (capital y resultados acumulados).

\section{Investigaciones relativas al estudio}


Se realizó la búsqueda de investigaciones relacionadas al análisis del retorno de la inversión comercial en supermercados utilizando métricas no financieras a escala nacional e internacional, pero no se hallaron trabajos aplicados similares. Sin embargo, se ha realizado un estudio respecto a las métricas no financieras y el retorno de la inversión en otras organizaciones. A continuación se indicarán los trabajos de investigación relacionados, que servirán como punto de partida para la propuesta de la presente investigación. Del mismo modo, se explicarán las métricas no financieras más relevantes, que han sido tratadas por Domínguez Doncel y Hermo Gutiérrez (2007) y Lenskold,(2003).

El antecedente más destacado con respecto al tema de investigación parece ser el estudio realizado por Leslier Valenzuela Fernández (2007), quien sostiene que los cambios y mejoras en el marketing orientado a la gestión del valor del cliente se debe, primero, a que las empresas comienzan a tomar conciencia del valor de la cartera de clientes y, segundo, a que se busca dar respuesta a la principal carencia del marketing, el hecho de no poder medir la productividad de las acciones de marketing.

La tesis de Valenzuela Fernández (2007) sostiene que los investigadores de marketing establecen el CLV (customer lifetime value) para cuantificar el valor del cliente a una escala individual, y el CE (customer equity) para medir y evaluar el desempeño financiero de la empresa en función de toda la base de clientes. Ambos modelos están directamente relacionados, pues el CE implica la agregación de los esperados valores del tiempo de vida de toda la base de clientes actuales y también de los futuros valores esperados del tiempo de vida de los clientes potenciales o recientemente adquiridos. Estos modelos son útiles para aplicarlos a medidas financieras como el EVA y el ROI, facilitando, por tanto, la evaluación de las inversiones de marketing (Valenzuela Fernández, 2007).

En su estudio, Valenzuela Fernández (2007) considera la gestión del valor del cliente bajo la perspectiva de la demanda y de la oferta. Por un lado, se reflexiona sobre la gestión del valor para el cliente (VC) como fuente de información imprescindible para determinar el potencial de rentabilidad de los clientes y seleccionar aquellos que permitan rentabilizar el negocio de la empresa y, por otro lado, se analiza la gestión del CE basada en acciones tácticas y estratégicas orientadas a maximizar el CLV de la cartera de clientes para aumentar el valor para la empresa.

Una conclusión que se extrae de la tesis de Valenzuela (2007) es que las empresas que toman decisiones estratégicas de marketing basadas en el CE mejoran su tasa de retención de clientes rentables, los ingresos generados por los clientes durante su tiempo de vida y también optimizan 
mejor sus costes de adquisición e inversión de clientes. Por lo tanto, las empresas que aumentan su tasa de retención de clientes rentables, que implementan estrategias para aumentar el nivel de gasto en el comportamiento de compra y que optimizan sus costes de inversión en clientes son las que declaran obtener un mayor nivel de utilidades, una mayor rentabilidad de su cuota de clientes y un mayor retorno sobre las inversiones de marketing (Valenzuela Fernández, 2007).

Valentina Anaïs Rodríguez Herrera (2013) menciona que la estimación del customer lifetime value a escala de clientes de un banco usando variables transaccionales y sociodemográficas ofrece grandes oportunidades en el negocio y mejora el retorno de la inversión del negocio a través de la captación de más consumidores.

A escala empresarial, concluye que la métrica del CLV es muy útil para seleccionar clientes rentables, gestionar campañas de retención, de segmentación y de desarrollo de la cartera de clientes. En consecuencia, el CLV y el CE son el puente entre el enfoque de marketing centrado en las compras y actitudes del cliente y el enfoque de finanzas centrada en el retorno de las inversiones y el valor de la empresa. Asimismo, resalta que el CLV es una métrica desagregada que puede ser usada para identificar a los clientes rentables y distribuir los recursos acorde al valor que estos clientes aportan al negocio, mientras que el CE, que considera el valor del tiempo de vida de los clientes actuales y potenciales, es una buena aproximación del valor global de la empresa.

Por último, destaca que una estrategia de gestión del valor del cliente es aplicable a cualquier industria y sector, especialmente en aquellos que disponen de gran cantidad de información sobre sus clientes, como el sector de servicios (supermercados, centros comerciales, banca, telecomunicaciones, etcétera) (Rodríguez Herrera, 2013).

El «valor del cliente en el largo plazo» (customer lifetime value, CLTV) es un indicador que nos permite saber cuánto vale cada cliente, en términos monetarios EI CLTV es una forma de medir el valor actual de los futuros flujos de caja atribuidos al patrón de consumo de un determinado cliente en nuestra empresa. Permite saber cuánto dinero puede aportar un determinado cliente en el futuro, si continúa con las mismas pautas de compra como hasta ahora.

La primera vez en la que aparece el término customer lifetime value en una publicación es por Shaw y Stone en su libro Database Marketing (1990), No solo puede usarse a escala de un cliente, sino también de un segmento de clientes. Por ejemplo, los más sensibles al precio o los que reconocen la velocidad en la atención, y los que van a los centros comerciales, etcétera. 
Obviamente, no es preciso que exista una tarjeta de plástico, sino cualquier método para identificar lo que hace un cliente. La principal ventaja del CLV respecto a las métricas habituales es que permite obtener una visión a largo plazo de la relación de los clientes con la empresa, y así tomar decisiones estratégicas. Por consiguiente, gestionar el valor del cliente implica optimizar cada aspecto que incrementa el valor del tiempo de vida del cliente (customer lifetime value, CLV) (Valenzuela \& Torres, 2008).

EI CLV es el beneficio o pérdida neta para la empresa desde un cliente sobre la total vida de las transacciones de aquel cliente con la firma. Para medir y evaluar el desempeño financiero de la empresa en función de toda la base de clientes, emerge la métrica customer equity (CE), que ha permitido a las empresas medir con mayor eficacia la productividad de las acciones de mercadeo (Valenzuela \& Torres, 2008). Según Hwang, Jung y Suh (2004 en Valenzuela \& Torres, 2008), el CE es la suma de todos los ingresos ganados desde todos los clientes de la empresa en el tiempo de vida de las transacciones después de la deducción del total de costes de atraer, vender y servir a los clientes, tomando en cuenta el valor del dinero en el tiempo.

Ambos conceptos están estrechamente relacionados, pues el CE se sustenta en la métrica del lifetime value de clientes individuales de la empresa, cuyo punto clave está en que el valor futuro del cliente introduce el concepto de potencialidad, lo que implica una visión estratégica del activo «cliente» (customer assets), en vez de una visión de corto plazo y netamente táctica. Es decir, se valora la cartera de clientes como el activo crítico para conseguir la rentabilidad del negocio, pues los flujos de ingresos se basan en las utilidades generadas por los clientes y las inversiones realizadas para generar esos beneficios (Valenzuela \& Torres, 2008).

Por lo tanto, la gestión del valor de la cartera de clientes significa determinar qué inversiones de cliente debería realizar la empresa y cómo debería realizarlas. Para ello, la compañía debería analizar en qué etapa de su ciclo de vida se encuentra el cliente y, posteriormente, determinar qué estrategias e inversiones de mercadeo se deberán implementar para lograr un crecimiento sostenible de los ingresos generados por cada cliente (Valenzuela \& Torres, 2008).

Así, las compañías podrán, en el mediano y largo plazos, incrementar el promedio del lifetime value de sus clientes y, por ende, lograr un mayor valor de su cartera de clientes. Por otra parte, las compañías requieren adaptar su infraestructura, procesos y sistemas de gestión que les permitan actualizar constantemente el conocimiento sobre sus clientes, analizar su valor y evaluar el intercambio de valor en la relación cliente empresa. Simultáneamente, esto permitirá que las 
compañías asignen los recursos con prioridad a los clientes con mayor valor, pues estos dirigen el éxito del negocio (Valenzuela \& Torres, 2008).

Durante muchos años la teoría y práctica del mercadeo han carecido de herramientas y métricas para demostrar cómo las inversiones y gastos en mercadeo pueden influir positivamente en la rentabilidad del negocio. Esta carencia ha debilitado la credibilidad de los gestores y ha amenazado la posición de esta función dentro de la empresa, pues se cuestiona la existencia del mercadeo como una capacidad o fortaleza trascendental en la organización (Hogan, Lemon \& Rust, 2002). Las compañías líderes han considerado este problema tan importante que el Marketing Science Institute (Instituto de Ciencia de Mercadeo) estableció que entre sus prioridades para el 2004-2006 estaba la evaluación de la productividad de las acciones de mercadeo y de las métricas utilizadas (Marketing Science Institute,2005) .

Hasta el momento existen muy pocos estudios empíricos sobre esta materia y la mayoría se basa en el cálculo del CLV. Además, están centrados en el valor actual neto obtenido desde los clientes sobre el tiempo de vida de las transacciones (Bayón, Gutsche \& Bauer, 2002; ; Berger \& Nasr 1998).

Son los modelos más recientes sobre el cálculo del CLV los que comienzan a orientarse al valor del cliente y a la rentabilidad de las relaciones. Por ejemplo, algunos de estos permiten medir cómo la duración del tiempo de vida del cliente en una posición no contractual puede ser rentable para la empresa o cómo la variable tiempo puede explicar el impacto de las características de las relaciones sobre la rentabilidad de la duración del tiempo de vida de la cartera de clientes (Reinartz \& Kumar 2000).

Por lo expuesto, es de gran importancia determinar el análisis de la inversión en la gestión comercial de los supermercados en el Perú utilizando métricas no financieras, pues, como vimos en el estudio anterior, considerar el valor del cliente en el largo plazo nos permite generar mayor valor al negocio. En consecuencia, un mayor retorno de la inversión.

Este trabajo presenta una propuesta innovadora, pues hasta la fecha no se ha realizado ningún estudio aplicado al análisis del retorno de la inversión comercial en los supermercados utilizando métricas no financieras, lo cual se comprobó en la estratégica de búsqueda sustentada en el proyecto de tesis doctoral a través los descriptores de ISI Web Science con el operador booleano OR que arrojó 0 resultados y AND apenas 63 temas relacionados en forma fraccionada. Por ello, se explica brevemente las tres etapas previas en las que se estructura esta nueva propuesta, luego se explicará los contenidos de estas etapas. 
Primera etapa: Se analizarán los estados financieros de los últimos cinco años de gestión de los supermercados más importantes en el Perú, convirtiendo sus valores corrientes a valores constantes de 2013, a base del ajuste de inflación de los valores corrientes por cada año.

Segunda etapa: Una vez convertido los estados financieros a valores constantes del último año de análisis, se aplicarán las métricas no financieras mencionadas en el estudio, a fin de ser analizadas financieramente y validadas estadísticamente para determinar cuáles son las que inciden en el retorno de la inversión en la gestión comercial de los supermercados en el Perú.

Tercera etapa: Las métricas no financieras se validan estadísticamente y luego se analizan financieramente los factores que determinan el retorno de la inversión en la gestión comercial de los supermercados en el Perú.

\section{Formulación de posibles hipótesis de trabajo}

En la presente investigación, las hipótesis se refieren a las explicaciones tentativas de las preguntas de investigación y los objetivos de la tesis:

\section{Hipótesis general}

El análisis del retorno de la inversión de los supermercados en el Perú utilizando métricas no financieras mejora la gestión comercial.

\section{Hipótesis específica 1}

El análisis del retorno de la inversión de los supermercados en el Perú utilizando métricas del mercado mejora la gestión comercial.

\section{Hipótesis específica 2}

El análisis del retorno de la inversión de los supermercados en el Perú utilizando métricas del cliente mejora la gestión comercial.

\section{Hipótesis específica 3}

El análisis del retorno de la inversión de los supermercados en el Perú utilizando métricas del supermercado mejora la gestión comercial.

\section{Metodología para contrastar las hipótesis}


La presente investigación propone analizar el retorno de la inversión comercial de los supermercados en el Perú a través de métricas no financieras.

A continuación se muestra la metodología propuesta, para aplicar las métricas no financieras al negocio de los supermercados en el Perú, la que puede ser aplicada a sectores de la economía peruana y mundial:

Figura 6 Metodología propuesta

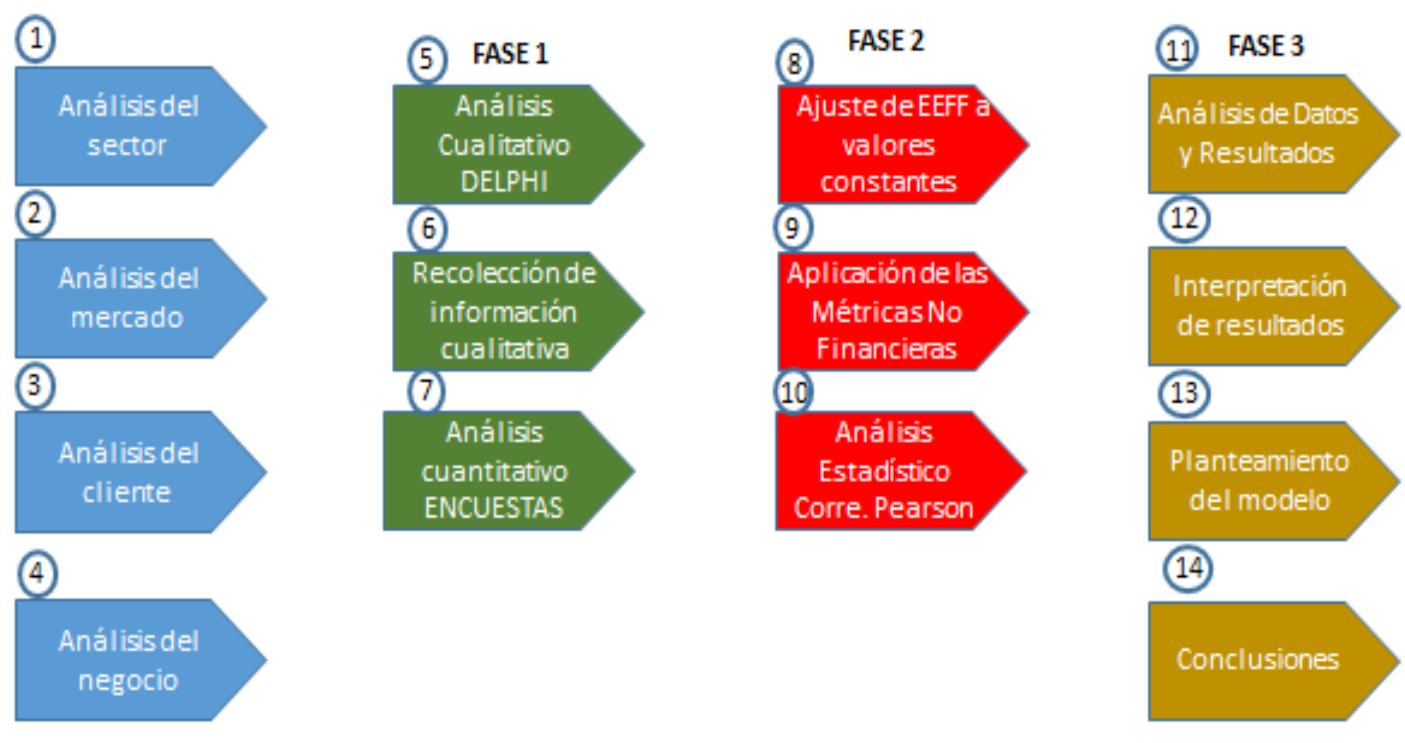

Elaboración propia

Cada número representa la secuencia a seguir para determinar el aporte del método, al generar valor para la gestión comercial y para el negocio de supermercados en el Perú.

La propuesta consta de tres fases y es la siguiente:

Primera fase: Es llamada fase cualitativa, porque se realizó una entrevista a expertos, para obtener información cualitativa acerca de las variables más importantes del negocio, siguiendo el método de juicio de expertos llamado Delphi (Linstone \& Turoff, 1975).

El método Delphi se engloba entre los métodos de prospectiva, que estudian el futuro, en lo que se refiere a la evolución de los factores del entorno tecno-socio-económico y sus interacciones.

Es un método de estructuración de un proceso de comunicación grupal, efectivo a la hora de permitir a un grupo de individuos, como un todo, tratar un problema complejo (Linstone \& Turoff, 1975). La capacidad de predicción de la Delphi se basa en la utilización sistemática de un juicio 
intuitivo emitido por un grupo de expertos. El objetivo de los cuestionarios sucesivos es «disminuir el espacio intercuartil, esto es cuanto se desvía la opinión del experto de la opinión del conjunto, precisando la mediana», de las respuestas obtenidas. Entre los métodos de pronóstico, habitualmente se clasifica al método Delphi dentro de los métodos cualitativos o subjetivos. La calidad de los resultados depende, sobre todo, del cuidado que se ponga en la elaboración del cuestionario y en la elección de los expertos consultados.

El resumen de los juicios de los expertos (en las formas de evaluaciones cuantitativas y comentarios escritos) es provisto como retroalimentación a los mismos expertos como partes de una ronda siguiente de cuestionario (next-round). A continuación, los expertos revalúan sus opiniones a la luz de esta información y un consenso de grupo tiende a emerger para realizar las conclusiones finales del estudio.

Segunda fase: En esta etapa cuantitativa se realizó una encuesta a los administradores de los supermercados en el Perú, para obtener información cuantitativa que valide el uso de las métricas no financieras en el análisis de la inversión en la gestión comercial de los supermercados en el Perú.

Para el respectivo cálculo, se utilizó la siguiente fórmula:

$n=\frac{N^{*} Z_{a}^{2} p^{*} q}{d^{2} *(N-1)+Z_{a}^{2} * p^{*} q}$

p: probabilidad de éxito, q: probabilidad de fracaso, $\mathrm{N}$ : población de supermercados, d: error muestral, Z: Distribución normal estandardizada.

A diciembre de 2013, el número de supermercados en el Perú ascendió a 237. Si se reemplaza este valor en la fórmula probabilística, el resultado de la muestra asciende a 147 supermercados. Es decir, se debe aplicar la encuesta a 147 administradores de supermercados.

La información que se solicita en la encuesta se relaciona con el conocimiento y manejo de los indicadores de las métricas no financieras por parte de los administradores de los supermercados. Luego se les solicita información numérica respecto a los indicadores, la que será utilizada para realizar el cálculo del retorno de la inversión para cada supermercado. 


\section{Método de correlación de Pearson}

Es una medida de relación lineal entre dos variables aleatorias cuantitativas. A diferencia de la covarianza, la correlación de Pearson es independiente de la escala de medida de las variables.

Este índice que puede utilizarse para medir el grado de relación de dos variables siempre y cuando ambas sea cuantitativo.

La escala de medición y calificación es la siguiente:

Correlación perfecta, cuando $r=1,00$

Correlación alta, cuando $0,70>r>0,90$

Correlación moderada, cuando $0,40>r>0,70$

Correlación baja, cuando $0,20>r>0,40$

Correlación escasa, cuando $0,01>r>0,20$

Correlación nula, cuando $r=0,00$

Tercera fase: Se analizan los datos y resultados. Se tomarán en cuenta las métricas no financieras que tengan alta correlación con el retorno de la inversión en la gestión comercial, como modelo de medición de la mejora del retorno de la inversión en la gestión comercial de los supermercados en el Perú.

Los resultados son interpretados, con énfasis en aquellas métricas que presenten mayor correlación con el retorno de la inversión en la gestión comercial. Luego se plantea el modelo metodológico, a base de las métricas que presenten mayor correlación al retorno de la inversión en la gestión comercial.

\section{Análisis de datos y principales resultados}

A continuación se muestran los resultados del método Delphi (entrevista a expertos) y la aplicación de las encuestas a escala prueba piloto, aplicada inicialmente a 20 administradores de supermercados. 
El instrumento elaborado en su etapa inicial fue aplicado a una muestra no probabilística de administradores de supermercados, considerando a quienes poseen experiencia en supermercados como mínimo cinco años.

Para elaborar el instrumento de recolección de datos, se determinaron las dimensiones e indicadores de las variables, según el siguiente cuadro:

Cuadro 1 Variables, dimensiones e indicadores

\begin{tabular}{lll}
\hline Variable & Dimensiones & Indicadores \\
\hline $\begin{array}{l}\text { Análisis del retorno de } \\
\text { la inversión }\end{array}$ & Inversión & ROI \\
& Valor del negocio & VAN \\
& Tasa de retorno del negocio & TIR \\
& Rentabilidad del negocio & Ebitda \\
Gestión comercial de & Métricas del mercado & $\begin{array}{l}\text { Cuota del mercado } \\
\text { los supermercados en } \\
\text { el Perú }\end{array}$ \\
& Métricas del cliente & $\begin{array}{l}\text { Penetración del mercado } \\
\text { Número de clientes }\end{array}$ \\
& & $\begin{array}{l}\text { Tique promedio } \\
\text { Rentabilidad del cliente }\end{array}$ \\
& Métricas del supermercado & $\begin{array}{l}\text { Rotación de inventarios } \\
\text { Ciclo operativo }\end{array}$ \\
& & $\begin{array}{l}\text { Ciclo de conversión de } \\
\text { efectivo }\end{array}$ \\
& &
\end{tabular}

Fuente: Elaboración propia

Se encuestaron a 147 administradores de supermercados en el Perú según la siguiente distribución:

Se seleccionaron tres grupos según su participación de mercado o share of market: Cencosud (Metro y Wong), con 40\% de participación; Interbank (Plaza Vea), 30\%, y Falabella (Tottus), 30\% (Cencosud 2009, 2010, 2011, 2012, 2013; Supermercados Peruanos, 2009, 2010, 2011, 2012 , 2013; Tottus, 2009, 2010, 2011, 2012, 2013).

Cuadro 2 Distribución de supermercados según su participación de mercado

\begin{tabular}{llllllll}
\hline $\begin{array}{l}\text { Grupos } \\
\text { económicos }\end{array}$ & SOM (\%) & M & W & PV & T & Total \\
\hline
\end{tabular}




\begin{tabular}{llllll}
\hline Grupo Cencosud & 40 & 30 & 29 & & 59 \\
Grupo Interbank & 30 & & 40 & & 44 \\
Grupo Falabella & 30 & & & 40 & 44 \\
\hline
\end{tabular}

147

Fuente: Cencosud 2009, 2010, 2011, 2012, 2013; Supermercados Peruanos, 2009, 2010, 2011, 2012, 2013; Tottus, 2009, 2010, 2011, 2012, 2013

Aproximadamente, Lima concentra el 70\% de supermercados en el Perú, por lo que se utilizó esa participación para seleccionar a los supermercados en Lima (capital del país) y en provincias (30\%). El siguiente cuadro muestra la distribución de supermercados a escala nacional.

Cuadro 3 Distribución de supermercados a escala nacional

\begin{tabular}{|c|c|c|c|c|c|}
\hline Grupos económicos & $\mathbf{M}$ & W & PV & $\mathbf{T}$ & Total \\
\hline Grupo Cencosud Lima & 21 & 21 & & & 42 \\
\hline $\begin{array}{l}\text { Grupo Cencosud } \\
\text { Provincias }\end{array}$ & 9 & 8 & & & 17 \\
\hline Grupo Interbank Lima & & & 31 & & 31 \\
\hline $\begin{array}{l}\text { Grupo Interbank } \\
\text { Provincias }\end{array}$ & & & 13 & & 13 \\
\hline Grupo Falabella Lima & & & & 31 & 31 \\
\hline $\begin{array}{l}\text { Grupo Falabella } \\
\text { Provincias }\end{array}$ & & & & 13 & 13 \\
\hline
\end{tabular}

Fuente: Elaboración propia en base a Cencosud 2009, 2010, 2011, 2012, 2013; Supermercados Peruanos, 2009, 2010, 2011, 2012, 2013; Tottus, 2009, 2010, 2011, 2012, 2013.

\section{Instrumento de análisis}

Se utilizó un cuestionario estructurado dirigido a 147 retailers o administradores de los supermercados en el Perú. El cuestionario consistió de veinte ítems, ordenados según sus variables, dimensiones e indicadores.

Validez y confiabilidad del instrumento

Se utilizó un cuestionario estructurado dirigido a 147 retailers. 
Instrumento: Cuestionario aplicado para conocer si el análisis del retorno de la inversión de los supermercados en el Perú utilizando métricas no financieras mejora la gestión comercial.

La fiabilidad del instrumento dirigido a las 147 retailers es considerada como consistencia interna de la prueba, alfa de Cronbach ( $\alpha=0,849)$, considerada como buena (Hernández Sampieri, 2006). Ello se ha determinado en relación a los veinte ítems centrales de la encuesta. Es decir, la encuesta realizada ha sido confiable, válida y aplicable. El cuadro 4 muestra los resultados del coeficiente de confiabilidad alfa de Cronbach. Las validaciones del instrumento se muestran en la sección de anexos.

\section{Cuadro 4 Estadístico de fiabilidad sobre el instrumento.}

Cuestionario aplicado para conocer si el análisis del retorno de la inversión de los supermercados en el Perú utilizando métricas no financieras mejora la gestión comercial

\begin{tabular}{|c|c|c|c|}
\hline \multicolumn{4}{|c|}{ Resumen del proceso } \\
\hline \multirow{4}{*}{$\begin{array}{l}\text { D } \\
\text { D్ } \\
\tilde{D} \\
0\end{array}$} & & $\mathrm{~N}$ & $\%$ \\
\hline & Validados & 147 & 100 \\
\hline & Excluidos & 0 & 0 \\
\hline & Total & 147 & 100 \\
\hline
\end{tabular}

Resultado estadístico

\begin{tabular}{cc}
\hline Alfa de Cronbach & Número de elementos \\
\hline 0.849 & 20 \\
\hline
\end{tabular}

A continuación se muestran los resultados obtenidos de la encuesta aplicada a 147 administradores de los supermercados en el Perú:

Tabla 1 Inversión en supermercados en el Perú

\begin{tabular}{lcc}
\hline \multicolumn{1}{c}{ Respuestas } & Frecuencia & Porcentaje \\
\hline Totalmente de acuerdo & 94 & $63.95 \%$ \\
\hline De acuerdo & 53 & $36.05 \%$ \\
\hline Ni de acuerdo ni en desacuerdo & 0 & $0 \%$ \\
\hline En desacuerdo & 0 & $0 \%$ \\
\hline Totalmente en desacuerdo & 0 & $0 \%$ \\
\hline
\end{tabular}

Zamudio Gutierrez, A. (2015). Análisis del retorno de la inversión en la gestión comercial de los supermercados en el Perú. Sinergia e Innovación, 3(1), 134-192. 
Fuente: Encuesta realizada a 147 administradores de supermercados en el Perú, noviembre de 2014.

La tabla 1 indica los resultados de la encuesta realizada a 147 retailers, que manifiestan respecto a si considera que las inversiones en el sector supermercados están en crecimiento en los últimos cinco años: 94 administradores refieren que están totalmente de acuerdo (63,95\%) y 53 administradores indican que están de acuerdo (36,05\%). Es decir, un 100\% de los encuestados están de acuerdo con respecto a que las inversiones en el sector supermercados están en crecimiento en los últimos cinco años.

Tabla 2 ROI y la gestión comercial de los supermercados en el Perú

\begin{tabular}{lccc}
\hline \multicolumn{1}{c}{ Respuestas } & Frecuencia & Porcentaje \\
\hline Totalmente de acuerdo & 86 & $58.50 \%$ \\
\hline De acuerdo & 61 & $41.50 \%$ \\
\hline Ni de acuerdo ni en desacuerdo & 0 & $0 \%$ \\
\hline En desacuerdo & 0 & $0 \%$ \\
\hline Totalmente en desacuerdo & 0 & $0 \%$ \\
\hline
\end{tabular}

Fuente: Encuesta realizada a 147 administradores de supermercados en el Perú, noviembre de 2014.

La tabla 2 indica los resultados de la encuesta realizada a 147 retailers, que manifiestan respecto a si considera que el análisis del retorno de la inversión (ROI) juega un papel importante en la gestión comercial de los supermercados en el Perú, 86 administradores refieren que están totalmente de acuerdo (58,50\%) y 61 administradores indican que están de acuerdo $(41,50 \%)$. Es decir, $100 \%$ de los encuestados están de acuerdo con respecto a si considera que el análisis del retorno de la inversión (ROI) juega un papel importante en la gestión comercial de los supermercados en el Perú.

Tabla 3 EI método del VAN y el valor del negocio

\begin{tabular}{lcc}
\hline \multicolumn{1}{c}{ Respuestas } & Frecuencia & Porcentaje \\
\hline Totalmente de acuerdo & 91 & $61.90 \%$ \\
\hline De acuerdo & 56 & $38.10 \%$ \\
\hline Ni de acuerdo ni en desacuerdo & 0 & $0 \%$ \\
\hline
\end{tabular}

Zamudio Gutierrez, A. (2015). Análisis del retorno de la inversión en la gestión comercial de los supermercados en el Perú. Sinergia e Innovación, 3(1), 134-192. 


\begin{tabular}{lccc}
\hline En desacuerdo & 0 & $0 \%$ \\
\hline Totalmente en desacuerdo & 0 & $0 \%$ \\
& TOTAL & 147 & $100 \%$ \\
\hline
\end{tabular}

Fuente: Encuesta realizada a 147 administradores de supermercados en el Perú, noviembre de 2014.

La tabla 3 indica los resultados de la encuesta realizada a 147 retailers, que manifiestan respecto a si el método del VAN es el indicado para determinar el valor del negocio en el sector supermercados, 91 administradores refieren que están totalmente de acuerdo $(61,90 \%)$ y 56 administradores indican que están de acuerdo (38,10\%). Es decir, 100\% de los encuestados están de acuerdo con que el método del VAN es el indicado para determinar el valor del negocio en el sector supermercados.

Tabla 4 EI método del TIR y la tasa de retorno de la inversión

\begin{tabular}{|c|c|c|}
\hline Respuestas & Frecuencia & Porcentaje \\
\hline Totalmente de acuerdo & 74 & $50.34 \%$ \\
\hline De acuerdo & 59 & $40.14 \%$ \\
\hline Ni de acuerdo ni en desacuerdo & 14 & $9.52 \%$ \\
\hline En desacuerdo & 0 & $0 \%$ \\
\hline \multirow[t]{2}{*}{ Totalmente en desacuerdo } & 0 & $0 \%$ \\
\hline & 147 & $100 \%$ \\
\hline
\end{tabular}

Fuente: Encuesta realizada a 147 administradores de supermercados en el Perú, noviembre de 2014.

La tabla 4 indica los resultados de la encuesta realizada a 147 retailers, que manifiestan respecto a si el método del TIR es el indicado para determinar la tasa de retorno de la inversión del negocio en el sector supermercados, 74 administradores refieren que están totalmente de acuerdo (50,34\%), 59 administradores indican que están de acuerdo (40,14\%) y 14 administradores manifiestan que están ni de acuerdo ni en desacuerdo (9,52\%). Es decir, más del $90 \%$ de los encuestados están de acuerdo con que el método del TIR es el indicado para determinar la tasa de retorno de la inversión del negocio en el sector supermercados.

Tabla 5 El método Ebitda y la rentabilidad del negocio

\begin{tabular}{lcc}
\hline \multicolumn{1}{c}{ Respuestas } & Frecuencia & Porcentaje \\
\hline Totalmente de acuerdo & 61 & $41.50 \%$ \\
\hline
\end{tabular}

Zamudio Gutierrez, A. (2015). Análisis del retorno de la inversión en la gestión comercial de los supermercados en el Perú. Sinergia e Innovación, 3(1), 134-192. 


\begin{tabular}{|c|c|c|}
\hline De acuerdo & 74 & $50.34 \%$ \\
\hline Ni de acuerdo ni en desacuerdo & 12 & $8.16 \%$ \\
\hline En desacuerdo & 0 & $0 \%$ \\
\hline Totalmente en desacuerdo & 0 & $0 \%$ \\
\hline TOTAL & 147 & $100 \%$ \\
\hline
\end{tabular}

Fuente: Encuesta realizada a 147 administradores de supermercados en el Perú, noviembre de 2014.

La tabla 5 indica los resultados de la encuesta realizada a 147 retailers, que manifiestan respecto a si el método Ebitda es el indicado para determinar la rentabilidad del negocio en el sector supermercados, 74 administradores refieren que están de acuerdo (50,34\%), 61 administradores indican que están totalmente acuerdo (41,50\%) y 12 administradores manifiestan que están ni de acuerdo ni en desacuerdo (8,16\%). Es decir, casi el 92\% de los encuestados están de acuerdo con que el método Ebitda es el indicado para determinar la rentabilidad del negocio en el sector supermercados.

Tabla 6 Nivel de importancia de las métricas financieras (promedio ponderado)

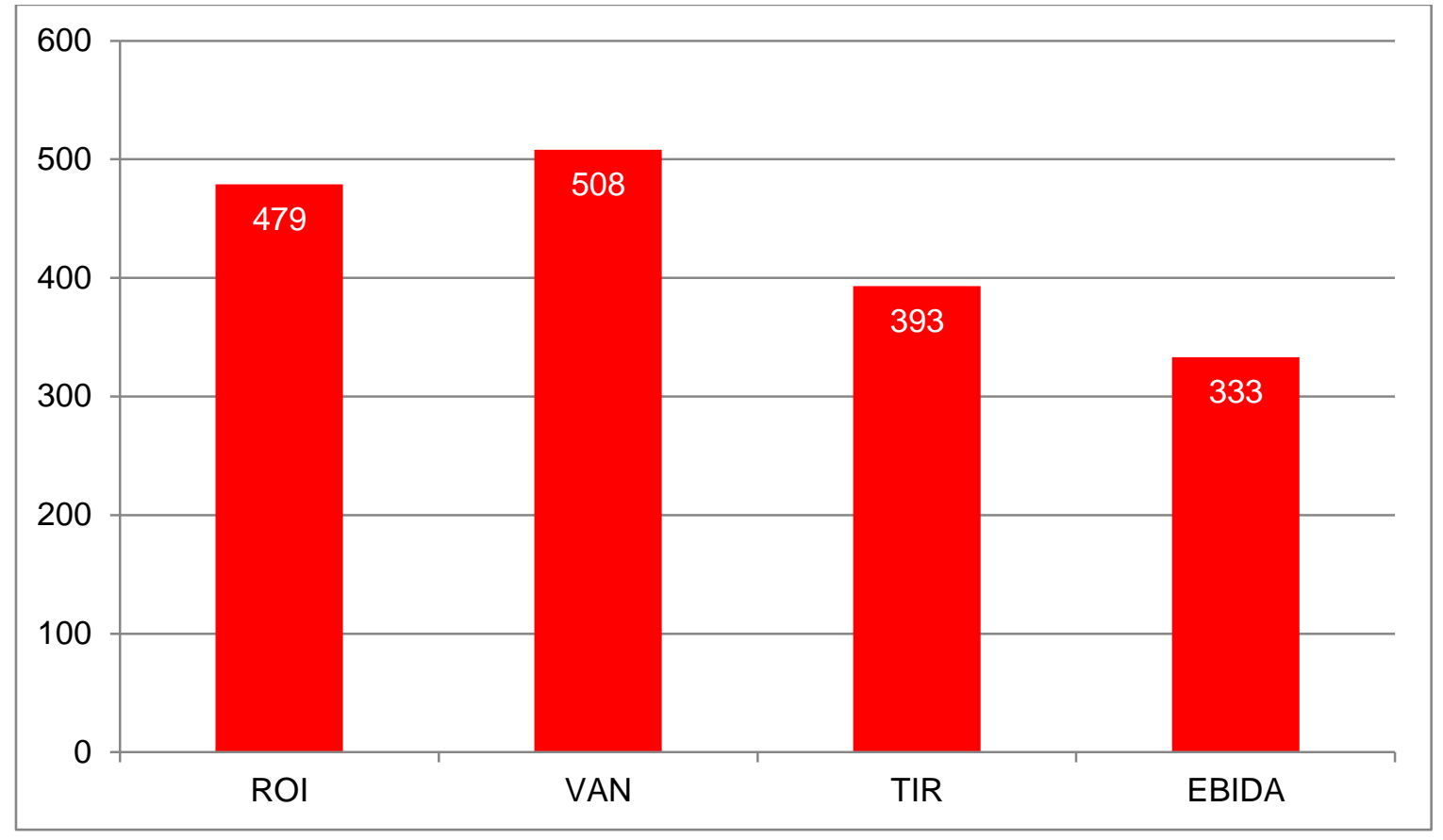

Fuente: Encuesta realizada a 147 administradores de supermercados en el Perú, noviembre de 2014.

La tabla 6 indica los resultados de la encuesta realizada a 147 retailers, que manifiestan respecto a la importancia que representa cada indicador financiero para el retorno de la inversión en la 
gestión comercial de los supermercados en el Perú. Los promedios ponderados para los indicadores financieros muestran que el indicador VAN es el que más puntaje ha obtenido con 508 puntos, le sigue el indicador ROI con 479 puntos, TIR con 393 puntos y finalmente Ebitda con 333 puntos. 
Tabla 7 La cuota del mercado y la gestión comercial de los supermercados en el Perú

\begin{tabular}{lccc}
\hline \multicolumn{1}{c}{ Respuestas } & Frecuencia & Porcentaje \\
\hline Totalmente de acuerdo & 40 & $27.21 \%$ \\
\hline De acuerdo & 94 & $63.95 \%$ \\
\hline Ni de acuerdo ni en desacuerdo & 13 & $8.84 \%$ \\
\hline En desacuerdo & 0 & $0 \%$ \\
\hline Totalmente en desacuerdo & 0 & $0 \%$ \\
\hline
\end{tabular}

Fuente: Encuesta realizada a 147 administradores de supermercados en el Perú, noviembre de 2014.

La tabla 7 indica los resultados de la encuesta realizada a 147 retailers, que manifiestan respecto a si la cuota del mercado se debe a la adecuada gestión comercial de los supermercados en el Perú, 94 administradores refieren que están de acuerdo (63,95\%), 40 administradores indican que están totalmente acuerdo $(27,21 \%)$ y 13 administradores manifiestan que están ni de acuerdo ni en desacuerdo (8,84\%). Es decir, más del $91 \%$ de los encuestados están de acuerdo con que la cuota del mercado se debe a la adecuada gestión comercial de los supermercados en el Perú

Tabla 8 La penetración del mercado y la gestión comercial de los supermercados en el Perú

\begin{tabular}{lccc}
\hline \multicolumn{1}{c}{ Respuestas } & Frecuencia & Porcentaje \\
\hline Totalmente de acuerdo & 93 & $63.27 \%$ \\
\hline De acuerdo & 39 & $26.53 \%$ \\
\hline Ni de acuerdo ni en desacuerdo & 15 & $10.20 \%$ \\
\hline En desacuerdo & 0 & $0 \%$ \\
\hline Totalmente en desacuerdo & 0 & $0 \%$ \\
& TOTAL & 147 & $100 \%$ \\
\hline
\end{tabular}

Fuente: Encuesta realizada a 147 administradores de supermercados en el Perú, noviembre de 2014.

La tabla 8 indica los resultados de la encuesta realizada a 147 retailers, que manifiestan respecto a la baja penetración del mercado de los supermercados en el Perú se debe a una inadecuada gestión comercial, 93 administradores refieren que están totalmente de acuerdo (63,27\%), 39 administradores indican que están acuerdo (26,53\%) y 15 administradores manifiestan que están ni de acuerdo ni en desacuerdo (10,20\%). Es decir, casi el $90 \%$ de los encuestados están de 
acuerdo con que la baja penetración del mercado de los supermercados en el Perú se debe a una inadecuada gestión comercial.

Tabla 9 Tique promedio del cliente y la gestión comercial de los supermercados en el Perú

\begin{tabular}{lccc}
\hline \multicolumn{1}{c}{ Respuestas } & Frecuencia & Porcentaje \\
\hline Totalmente de acuerdo & 0 & $0 \%$ \\
\hline De acuerdo & 0 & $0 \%$ \\
\hline Ni de acuerdo ni en desacuerdo & 16 & $10.88 \%$ \\
\hline En desacuerdo & 75 & $51.02 \%$ \\
\hline Totalmente en desacuerdo & 56 & $38.10 \%$ \\
\hline
\end{tabular}

Fuente: Encuesta realizada a 147 administradores de supermercados en el Perú, noviembre de 2014.

La tabla 9 indica los resultados de la encuesta realizada a 147 retailers, que manifiestan respecto a si la eficacia del cliente a través de la gestión comercial de los supermercados en el Perú es adecuada, 75 administradores refieren que están en desacuerdo (51,02\%), 56 administradores indican que están totalmente en desacuerdo (38,10\%) y 16 administradores manifiestan que están ni de acuerdo ni en desacuerdo (10,88\%). Es decir, más del $89 \%$ de los encuestados están en desacuerdo con que la eficacia del cliente a través de la gestión comercial de los supermercados en el Perú es adecuada.

Tabla 10 Número de clientes y gestión comercial de los supermercados en el Perú

\begin{tabular}{lccc}
\hline \multicolumn{1}{c}{ Respuestas } & Frecuencia & Porcentaje \\
\hline Totalmente de acuerdo & 0 & $0 \%$ \\
\hline De acuerdo & 0 & $0 \%$ \\
\hline Ni de acuerdo ni en desacuerdo & 7 & $4.76 \%$ \\
\hline En desacuerdo & 90 & $61.23 \%$ \\
\hline Totalmente en desacuerdo & 50 & $34.01 \%$ \\
\hline
\end{tabular}

Fuente: Encuesta realizada a 147 administradores de supermercados en el Perú, noviembre de 2014.

La tabla 10, indica los resultados de la encuesta realizada a 147 retailers, que manifiestan respecto a si la eficiencia del cliente a través de la gestión comercial de los supermercados en el 
Perú es adecuada, 90 administradores refieren que están en desacuerdo (61,23\%), 50 administradores indican que están totalmente en desacuerdo (34,01\%) y 7 administradores manifiestan que están ni de acuerdo ni en desacuerdo (4,76\%). Es decir, más del 95\% de los encuestados están en desacuerdo con que la eficiencia del cliente a través de la gestión comercial de los supermercados en el Perú es adecuada.

Tabla 11 La rentabilidad del cliente y la gestión comercial de los supermercados en el Perú

\begin{tabular}{|c|c|c|}
\hline Respuestas & Frecuencia & Porcentaje \\
\hline Totalmente de acuerdo & 0 & $0 \%$ \\
\hline De acuerdo & 0 & $0 \%$ \\
\hline Ni de acuerdo ni en desacuerdo & 5 & $3.40 \%$ \\
\hline En desacuerdo & 82 & $55.78 \%$ \\
\hline \multirow[t]{2}{*}{ Totalmente en desacuerdo } & 60 & $40.82 \%$ \\
\hline & 147 & $100 \%$ \\
\hline
\end{tabular}

Fuente: Encuesta realizada a 147 administradores de supermercados en el Perú, noviembre de 2014.

La tabla 11 indica los resultados de la encuesta realizada a 147 retailers, que manifiestan respecto a si la rentabilidad del cliente a través de la gestión comercial de los supermercados en el Perú es adecuada, 82 administradores refieren que están en desacuerdo (55,78\%), 60 administradores indican que están totalmente en desacuerdo (40,82\%) y 5 administradores manifiestan que están ni de acuerdo ni en desacuerdo (3,40\%). Es decir, más del $96 \%$ de los encuestados están en desacuerdo con que la rentabilidad del cliente a través de la gestión comercial de los supermercados en el Perú es adecuada.

Tabla 12 La medición del valor del cliente a través de la gestión comercial de los supermercados en el Perú

\begin{tabular}{|c|c|c|}
\hline Respuestas & Frecuencia & Porcentaje \\
\hline Totalmente de acuerdo & 0 & $0 \%$ \\
\hline De acuerdo & 0 & $0 \%$ \\
\hline Ni de acuerdo ni en desacuerdo & 2 & $1.36 \%$ \\
\hline En desacuerdo & 108 & $73.47 \%$ \\
\hline Totalmente en desacuerdo & 37 & $25.17 \%$ \\
\hline TOTAL & 147 & $100 \%$ \\
\hline
\end{tabular}

Fuente: Encuesta realizada a 147 administradores de supermercados en el Perú, noviembre de 2014. 
La tabla 12 indica los resultados de la encuesta realizada a 147 retailers, que manifiestan respecto a si la medición del valor del cliente a través de la gestión comercial de los supermercados en el Perú es adecuada. 108 administradores refieren que están en desacuerdo (73,47\%), 37 administradores indican que están totalmente en desacuerdo (25,17\%) y 2 administradores manifiestan que están ni de acuerdo ni en desacuerdo (1,36\%). Es decir, más del $98 \%$ de los encuestados están en desacuerdo con que la medición del valor del cliente a través de la gestión comercial de los supermercados en el Perú es adecuada.

Tabla 13 El nivel de rotación de inventarios y la gestión comercial de los supermercados en el Perú

\begin{tabular}{|c|c|c|}
\hline Respuestas & Frecuencia & Porcentaje \\
\hline Totalmente de acuerdo & 0 & $0 \%$ \\
\hline De acuerdo & 0 & $0 \%$ \\
\hline Ni de acuerdo ni en desacuerdo & 4 & $2.72 \%$ \\
\hline En desacuerdo & 97 & $65.99 \%$ \\
\hline Totalmente en desacuerdo & 46 & $31.29 \%$ \\
\hline TOTAL & 147 & $100 \%$ \\
\hline
\end{tabular}

Fuente: Encuesta realizada a 147 administradores de supermercados en el Perú, noviembre de 2014.

La tabla 13 indica los resultados de la encuesta realizada a 147 retailers, que manifiestan respecto a si el nivel de rotación de inventarios a través de la gestión comercial de los supermercados en el Perú es adecuada. 97 administradores refieren que están en desacuerdo (65,99\%), 46 administradores indican que están totalmente en desacuerdo $(31,29 \%)$ y 4 administradores manifiestan que están ni de acuerdo ni en desacuerdo (2,72\%). Es decir, más del $97 \%$ de los encuestados están en desacuerdo con que el nivel de rotación de inventarios a través de la gestión comercial de los supermercados en el Perú es adecuado.

Tabla 14 El ciclo operativo y la gestión comercial de los supermercados en el Perú

\begin{tabular}{lcc}
\hline \multicolumn{1}{c}{ Respuestas } & Frecuencia & Porcentaje \\
\hline Totalmente de acuerdo & 0 & $0 \%$ \\
\hline De acuerdo & 0 & $0 \%$ \\
\hline Ni de acuerdo ni en desacuerdo & 3 & $2.04 \%$ \\
\hline En desacuerdo & 75 & $51.02 \%$ \\
\hline Totalmente en desacuerdo & 69 & $46.94 \%$ \\
\hline
\end{tabular}

Zamudio Gutierrez, A. (2015). Análisis del retorno de la inversión en la gestión comercial de los supermercados en el Perú. Sinergia e Innovación, 3(1), 134-192. 
Fuente: Encuesta realizada a 147 administradores de supermercados en el Perú, noviembre de 2014.

La tabla 14 indica los resultados de la encuesta realizada a 147 retailers, que manifiestan respecto a si el ciclo operativo a través de la gestión comercial de los supermercados en el Perú es adecuada. 75 administradores refieren que están en desacuerdo (51,02\%), 69 administradores indican que están totalmente en desacuerdo (46,94\%) y 3 administradores manifiestan que están ni de acuerdo ni en desacuerdo (2,04\%). Es decir, casi el 98\% de los encuestados están en desacuerdo con que el ciclo operativo a través de la gestión comercial de los supermercados en el Perú es adecuado.

Tabla 15 El ciclo de conversión de efectivo a través de la gestión comercial de los supermercados en el Perú es adecuado

\begin{tabular}{lccc}
\hline \multicolumn{1}{c}{ Respuestas } & Frecuencia & Porcentaje \\
\hline Totalmente de acuerdo & 0 & $0 \%$ \\
\hline De acuerdo & 0 & $0 \%$ \\
\hline Ni de acuerdo ni en desacuerdo & 8 & $5.44 \%$ \\
\hline En desacuerdo & 83 & $56.46 \%$ \\
\hline Totalmente en desacuerdo & 56 & $38.10 \%$ \\
\hline
\end{tabular}

Fuente: Encuesta realizada a 147 administradores de supermercados en el Perú, noviembre de 2014.

La tabla 15 indica los resultados de la encuesta realizada a 147 administradores de supermercados en el Perú, que manifiestan respecto a si el ciclo de conversión de efectivo a través de la gestión comercial de los supermercados en el Perú es adecuada. 83 administradores refieren que están en desacuerdo (56,46\%), 56 administradores indican que están totalmente en desacuerdo $(38,10 \%)$ y 8 administradores manifiestan que están ni de acuerdo ni en desacuerdo (5,44\%). Es decir, casi el 95\% de los encuestados están en desacuerdo con que el ciclo de conversión de efectivo a través de la gestión comercial de los supermercados en el Perú es adecuado.

Tabla 16 Importancia del retorno de la inversión a través de métricas no financieras

\begin{tabular}{lcc}
\hline \multicolumn{1}{c}{ Respuestas } & Frecuencia & Porcentaje \\
\hline Totalmente de acuerdo & 24 & $16.33 \%$ \\
\hline $\begin{array}{l}\text { supermercados en el Perú. Sinergia e Innovación, 3(1), 134-192. } \\
\text { sudio Gutierrez, A. (2015). Análisis del retorno de la inversión en la gestión comercial de los }\end{array}$ & 171 \\
\hline
\end{tabular}




\begin{tabular}{|c|c|c|}
\hline De acuerdo & 74 & $50.34 \%$ \\
\hline Ni de acuerdo ni en desacuerdo & 49 & $33.33 \%$ \\
\hline En desacuerdo & 0 & $0 \%$ \\
\hline Totalmente en desacuerdo & 0 & $0 \%$ \\
\hline TOTAL & 147 & $100 \%$ \\
\hline
\end{tabular}

Fuente: Encuesta realizada a 147 administradores de supermercados en el Perú, noviembre de 2014.

La tabla 16, indica los resultados de la encuesta realizada a 147 retailers, que manifiestan respecto a si es importante medir el retorno de la inversión a través de métricas no financieras, para la mejora en la gestión comercial de los supermercados en el Perú. 74 administradores refieren que están de acuerdo (50,34\%), 49 administradores indican que están ni de acuerdo ni en desacuerdo $(33,33 \%)$ y 24 administradores manifiestan que están totalmente de acuerdo (16,33\%). Es decir, casi el $66 \%$ de los encuestados están en de acuerdo con que es importante medir el retorno de la inversión a través de métricas no financieras, para la mejora en la gestión comercial de los supermercados en el Perú.

Tabla 17 Métricas del mercado y la gestión comercial de los supermercados en el Perú

\begin{tabular}{lccc}
\hline \multicolumn{1}{c}{ Respuestas } & Frecuencia & Porcentaje \\
\hline Totalmente de acuerdo & 49 & $33.33 \%$ \\
\hline De acuerdo & 96 & $65.31 \%$ \\
\hline Ni de acuerdo ni en desacuerdo & 2 & $1.36 \%$ \\
\hline En desacuerdo & 0 & $0 \%$ \\
\hline Totalmente en desacuerdo & 0 & $0 \%$ \\
\hline
\end{tabular}

Fuente: Encuesta realizada a 147 administradores de supermercados en el Perú, noviembre de 2014.

La tabla 17 indica los resultados de la encuesta realizada a 147 retailers, que manifiestan respecto a si medir el retorno de la inversión a través de métricas del mercado, aportará a una mejor gestión comercial de los supermercados en el Perú, para la mejora en la gestión comercial de los supermercados en el Perú. 96 administradores refieren que están en de acuerdo (65,31\%), 49 administradores indican que están totalmente de acuerdo (33,33\%) y 2 administradores manifiestan que están ni de acuerdo ni en desacuerdo (1,36\%). Es decir, casi el 99\% de los 
encuestados están en de acuerdo con que medir el retorno de la inversión a través de métricas del mercado, aportará a una mejor gestión comercial de los supermercados en el Perú.

Tabla 18 Métricas del cliente y la gestión comercial de los supermercados en el Perú

\begin{tabular}{|c|c|c|}
\hline Respuestas & Frecuencia & Porcentaje \\
\hline Totalmente de acuerdo & 83 & $56.46 \%$ \\
\hline De acuerdo & 59 & $40.14 \%$ \\
\hline Ni de acuerdo ni en desacuerdo & 5 & $3.40 \%$ \\
\hline En desacuerdo & 0 & $0 \%$ \\
\hline \multirow[t]{2}{*}{ Totalmente en desacuerdo } & 0 & $0 \%$ \\
\hline & 147 & $100 \%$ \\
\hline
\end{tabular}

Fuente: Encuesta realizada a 147 administradores de supermercados en el Perú, noviembre de 2014.

La tabla 18 indica los resultados de la encuesta realizada a 147 retailers, que manifiestan respecto a si medir el retorno de la inversión a través de métricas del cliente, aportará a una mejor gestión comercial de los supermercados en el Perú, aportará a una mejor gestión comercial de los supermercados en el Perú, para la mejora en la gestión comercial de los supermercados en el Perú. 83 administradores refieren que están totalmente de acuerdo (56,46\%), 59 administradores indican que están de acuerdo $(40,14 \%)$ y 5 administradores manifiestan que están ni de acuerdo ni en desacuerdo (3,40\%). Es decir, el 97\% de los encuestados están en de acuerdo con que medir el retorno de la inversión a través de métricas del cliente, aportará a una mejor gestión comercial de los supermercados en el Perú.

Tabla 19 Métricas del supermercado y la gestión comercial de los supermercados en el Perú

\begin{tabular}{|c|c|c|}
\hline Respuestas & Frecuencia & Porcentaje \\
\hline Totalmente de acuerdo & 75 & $51.02 \%$ \\
\hline De acuerdo & 61 & $41.50 \%$ \\
\hline Ni de acuerdo ni en desacuerdo & 11 & $7.48 \%$ \\
\hline En desacuerdo & 0 & $0 \%$ \\
\hline Totalmente en desacuerdo & 0 & $0 \%$ \\
\hline TOTAL & 147 & $100 \%$ \\
\hline
\end{tabular}

Fuente: Encuesta realizada a 147 administradores de supermercados en el Perú, noviembre de 2014. 
La tabla 19 indica los resultados de la encuesta realizada a 147 retailers, que manifiestan respecto a si medir el retorno de la inversión a través de métricas del supermercado, aportará a una mejor gestión comercial de los supermercados en el Perú, aportará a una mejor gestión comercial de los supermercados en el Perú, para la mejora en la gestión comercial de los supermercados en el Perú. 75 administradores refieren que están totalmente de acuerdo (51,02\%), 61 administradores indican que están de acuerdo $(41,50 \%)$ y 11 administradores manifiestan que están ni de acuerdo ni en desacuerdo (7,48\%). Es decir, casi el 93\% de los encuestados están en de acuerdo con que medir el retorno de la inversión a través de métricas del supermercado, aportará a una mejor gestión comercial de los supermercados en el Perú.

Tabla 20 Nivel de importancia de las métricas no financieras

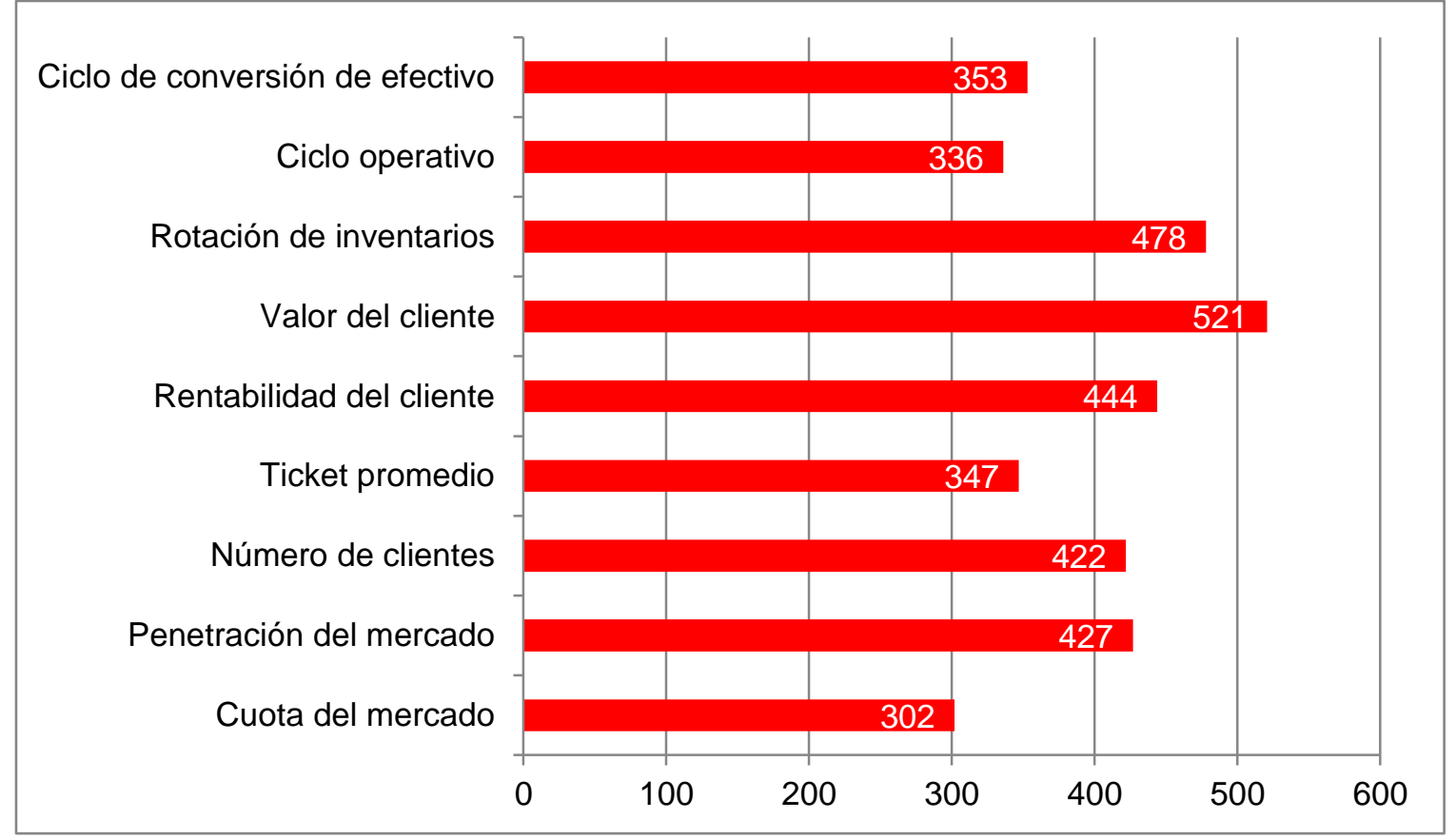

Fuente: Encuesta realizada a 147 administradores de supermercados en el Perú, noviembre de 2014.

La tabla 20 indica los resultados de la encuesta realizada a 147 administradores de supermercados en el Perú, que manifiestan respecto a la importancia que representa cada indicador no financiero para el retorno de la inversión en la gestión comercial de los supermercados en el Perú. Los promedios ponderados para los indicadores financieros muestran que los indicadores: Valor del cliente, rotación de inventarios y rentabilidad del cliente son los que más puntaje han obtenido, con 521,478 y 444 , respectivamente. 


\subsection{Contrastación de hipótesis}

Se han contrastado y comprobado las tres hipótesis específicas por lo que queda contrastada y comprobada la hipótesis general.

\section{Hipótesis general}

El análisis del retorno de la inversión de los supermercados en el Perú utilizando métricas no financieras mejora la gestión comercial.

\section{Hipótesis nula}

El análisis del retorno de la inversión de los supermercados en el Perú utilizando métricas no financieras no mejora la gestión comercial.

Para comprobar la hipótesis general a través de cada una de las hipótesis específicas, se ha procedido a utilizar la prueba estadística de correlación producto momento de Pearson, que se aplica para medir variables cuantitativas como en el presente estudio. Se han considerado para la prueba estadística los resultados de las 147 encuestas realizadas a los retailers.

Se presentan a continuación cada hipótesis específica con las tablas producto de la aplicación del paquete estadístico de Ciencias Sociales SPSS versión 23.

\section{Hipótesis específica 1}

El análisis del retorno de la inversión de los supermercados en el Perú utilizando métricas del mercado mejora la gestión comercial.

\section{Hipótesis nula}

El análisis del retorno de la inversión de los supermercados en el Perú utilizando métricas del mercado no mejora la gestión comercial.

Tabla 21 Correlación entre métricas de mercado y gestión comercial

\begin{tabular}{llrr}
\hline Correlaciones & \multicolumn{2}{c}{$\begin{array}{c}\text { Métricas del } \\
\text { mercado }\end{array}$} & Gestión comercial \\
\hline $\begin{array}{l}\text { Métricas del } \\
\text { mercado }\end{array}$ & Correlación de Pearson & 1 & $0.905^{\star \star}$ \\
& Sig. (bilateral) & 147 & 0.000 \\
& $\mathrm{~N}$ & $0.905^{\star *}$ & 147 \\
$\begin{array}{l}\text { Gestión } \\
\text { comercial }\end{array}$ & Correlación de Pearson & 0.000 & 1 \\
& Sig. (bilateral) & & \\
\hline
\end{tabular}


** La correlación es significativa al nivel 0,01 (bilateral)

Toma de decisión: dado que el resultado de la correlación producto momento de Pearson es igual a 0,905, se rechaza la hipótesis nula y se acepta la hipótesis alternativa queda demostrado que el análisis del retorno de la inversión de los supermercados en el Perú utilizando métricas del mercado mejora la gestión comercial. La correlación resulta ser significativa y muy intensa (de 0,90 a 0,99). Este resultado es corroborado por la prueba de significación bilateral cuyo resultado es 0,000 menor que la probabilidad de error de 0,01 .

\section{Hipótesis específica 2}

El análisis del retorno de la inversión de los supermercados en el Perú utilizando métricas del cliente mejora la gestión comercial.

\section{Hipótesis nula}

El análisis del retorno de la inversión de los supermercados en el Perú utilizando métricas del cliente no mejora la gestión comercial.

Tabla 22 Correlación entre métricas del cliente y gestión comercial

\begin{tabular}{llrr}
\hline Correlaciones & Métricas del cliente & Gestión comercial \\
\hline $\begin{array}{llr}\text { Métricas del } \\
\text { cliente }\end{array}$ & Correlación de Pearson & 1 & $0.898^{* *}$ \\
& Sig. (bilateral) & & 0.000 \\
& $\mathrm{~N}$ & 147 & 147 \\
Gestión & Correlación de Pearson & $0.898^{* *}$ & 1 \\
comercial & Sig. (bilateral) & 0.000 & 147 \\
& $\mathrm{~N}$ & 147 & \\
\hline
\end{tabular}

Toma de decisión: dado que el resultado de la correlación producto momento de Pearson es igual a 0,898 se rechaza la hipótesis nula y se acepta la hipótesis alternativa, queda demostrado que el análisis del retorno de la inversión de los supermercados en el Perú utilizando métricas del cliente mejora la gestión comercial. La correlación resulta ser significativa y alta (de 0,70 a 0,90). Este resultado es corroborado por la prueba de significación bilateral cuyo resultado es 0,000 menor que la probabilidad de error de 0,01 . 


\section{Hipótesis específica 3}

El análisis del retorno de la inversión de los supermercados en el Perú utilizando métricas del supermercado mejora la gestión comercial.

\section{Hipótesis nula}

El análisis del retorno de la inversión de los supermercados en el Perú utilizando métricas del supermercado no mejora la gestión comercial.

Tabla 23 Correlación entre métricas del supermercado y gestión comercial

\begin{tabular}{llrr}
\hline Correlaciones & $\begin{array}{c}\text { Métricas del } \\
\text { supermercado }\end{array}$ & Gestión comercial \\
\hline $\begin{array}{llr}\text { Métricas del } \\
\text { negocio }\end{array}$ & Correlación de Pearson & 1 & $0.906^{\star \star}$ \\
& Sig. (bilateral) & 147 & 0.000 \\
& $\mathrm{~N}$ & $0.906^{* *}$ & 147 \\
Gestión & Correlación de Pearson & 0.000 & 1 \\
comercial & Sig. (bilateral) & 147 & 147 \\
& $\mathrm{~N}$ & &
\end{tabular}

Toma de decisión: dado que el resultado de la correlación producto momento de Pearson es igual a 0,906 se rechaza la hipótesis nula y se acepta la hipótesis alternativa queda demostrado que el análisis del retorno de la inversión de los supermercados en el Perú utilizando métricas del supermercado mejora la gestión comercial. La correlación resulta ser significativa y muy intensa (de 0,90 a 0,99). Este resultado es corroborado por la prueba de significación bilateral cuyo resultado es 0,000 menor que la probabilidad de error de 0,01 , que es el valor con mayor rigor científico.

Se comprobaron las tres hipótesis específicas, por lo que la hipótesis general quedó comprobada, es decir:

El análisis del retorno de la inversión de los supermercados en el Perú utilizando métricas no financieras mejora la gestión comercial.

\subsection{Resultados inferenciales adicionales a la comprobación de hipótesis}

Ahora se presentan algunos resultados inferenciales para tratar de encontrar cuál o cuáles son las métricas que están más relacionadas a la gestión comercial considerando en forma separada 
cada uno de los indicadores de las dimensiones de la variable análisis del retorno de la inversión de los supermercados en el Perú utilizando métricas del mercado, del cliente y del negocio.

\section{Métricas del mercado}

\section{Cuota de mercado}

Tabla 24 Correlación entre cuota de mercado y gestión comercial

\begin{tabular}{llrr}
\hline Correlaciones & Cuota de mercado & Gestión comercial \\
\hline $\begin{array}{llr}\text { Cuota de } \\
\text { mercado }\end{array}$ & Correlación de Pearson & 1 & $0.814^{* *}$ \\
& Sig. (bilateral) & & 0.000 \\
& $\mathrm{~N}$ & 147 & 147 \\
Gestión & Correlación de Pearson & $0.814^{* *}$ & 1 \\
comercial & Sig. (bilateral) & 0.000 & 147 \\
& $\mathrm{~N}$ & 147 & \\
\hline
\end{tabular}

Según los resultados obtenidos mediante la correlación producto momento de Pearson encontramos que el indicador cuota de mercado permite la mejora de la gestión comercial, ello se puede comprobar porque en la tabla se observa que el valor resultante de 0,814 es significativo, indicando una correlación alta (de 0,70 a 0,90 ) El resultado es corroborado mediante la prueba de significación bilateral de 0,000 menor a la probabilidad de 0,01.

\section{Penetración de mercado}

Tabla 25 Correlación entre penetración de mercado y gestión comercial

\begin{tabular}{llrr}
\hline Correlaciones & & $\begin{array}{c}\text { Penetración de } \\
\text { mercado }\end{array}$ & Gestión comercial \\
\hline $\begin{array}{l}\text { Penetración } \\
\text { de mercado }\end{array}$ & Correlación de Pearson & 1 & $0.845^{\star *}$ \\
& Sig. (bilateral) & 147 & 0.000 \\
& $\mathrm{~N}$ & $0.845^{\star *}$ & 147 \\
Gestión & Correlación de Pearson & 0.000 & 1 \\
comercial & Sig. (bilateral) & 147 & 147 \\
\hline
\end{tabular}

Zamudio Gutierrez, A. (2015). Análisis del retorno de la inversión en la gestión comercial de los supermercados en el Perú. Sinergia e Innovación, 3(1), 134-192. 
** La correlación es significativa al nivel 0,01 (bilateral).

Según los resultados obtenidos mediante la correlación producto momento de Pearson encontramos que el indicador penetración de mercado permite la mejora de la gestión comercial, ello se puede comprobar porque en la tabla se observa que el valor resultante de 0,845 es significativo, indicando una correlación alta (de 0,70 a 0,90) El resultado es corroborado mediante la prueba de significación bilateral de 0,000 menor a la probabilidad de 0,01.

Este indicador sería el más significativo en cuanto a la dimensión métrica del mercado.

\section{Métricas del cliente}

Tique promedio

Tabla 26 Correlación entre tique promedio y gestión comercial

\begin{tabular}{llrr}
\hline Correlaciones & Tique promedio & Gestión comercial \\
\hline $\begin{array}{l}\text { Tique } \\
\text { promedio }\end{array}$ & Correlación de Pearson & 1 & $0.718^{* *}$ \\
& Sig. (bilateral) & & 0.000 \\
& $\mathrm{~N}$ & 147 & 147 \\
Gestión & Correlación de Pearson & $0.718^{* *}$ & 1 \\
comercial & Sig. (bilateral) & 0.000 & 147 \\
& $\mathrm{~N}$ & 147 &
\end{tabular}

Según los resultados obtenidos mediante la correlación producto momento de Pearson encontramos que el indicador tique promedio permite la mejora de la gestión comercial, ello se puede comprobar porque en la tabla se observa que el valor resultante de 0,718 es significativo, indicando una correlación alta (de 0,70 a 0,90) El resultado es corroborado mediante la prueba de significación bilateral de 0,000 menor a la probabilidad de 0,01.

\section{Número de clientes}

Tabla 27 Correlación entre número de clientes y gestión comercial

\begin{tabular}{lrrr}
\hline Correlaciones & Número de clientes & Gestión comercial \\
\hline Número de & Correlación de Pearson & 1 & $0.836^{* *}$ \\
\hline
\end{tabular}

Zamudio Gutierrez, A. (2015). Análisis del retorno de la inversión en la gestión comercial de los supermercados en el Perú. Sinergia e Innovación, 3(1), 134-192. 


\begin{tabular}{llrr}
\hline clientes & Sig. (bilateral) & 0.000 \\
& N & 147 & 147 \\
Gestión & Correlación de Pearson & $0.836^{* *}$ & 1 \\
comercial & Sig. (bilateral) & 0.000 & \\
& N & 147 & 147 \\
\hline
\end{tabular}

** La correlación es significativa al nivel 0,01 (bilateral).

Según los resultados obtenidos mediante la correlación producto momento de Pearson encontramos que el indicador número de clientes permite la mejora de la gestión comercial, ello se puede comprobar porque en la tabla se observa que el valor resultante de 0,836 es significativo, indicando una correlación alta (de 0,70 a 0,90) El resultado es corroborado mediante la prueba de significación bilateral de 0,000 menor a la probabilidad de 0,01.

\section{Rentabilidad del cliente}

Tabla 28 Correlación entre rentabilidad del cliente y gestión comercial

\begin{tabular}{llrr}
\hline Correlaciones & \multicolumn{2}{c}{$\begin{array}{c}\text { Rentabilidad del } \\
\text { cliente }\end{array}$} & Gestión comercial \\
\hline $\begin{array}{l}\text { Rentabilidad } \\
\text { del cliente }\end{array}$ & Correlación de Pearson & 1 & $0.867^{* *}$ \\
& Sig. (bilateral) & 147 & 0.000 \\
& $\mathrm{~N}$ & $0.867^{* *}$ & 147 \\
Gestión & Correlación de Pearson & 0.000 & 1 \\
comercial & Sig. (bilateral) & 147 & 147 \\
& $\mathrm{~N}$ & &
\end{tabular}

Observamos en la tabla que el indicador rentabilidad del cliente permite la mejora de la gestión comercial, ello se puede comprobar porque en la tabla se observa que el valor resultante de 0,867 es significativo, indicando una correlación alta (de 0,70 a 0,90 ) El resultado es corroborado mediante la prueba de significación bilateral de 0,000 menor a la probabilidad de 0,01. 
Valor del cliente

Tabla 29 Correlación entre valor del cliente y gestión comercial

\begin{tabular}{llrr}
\hline Correlaciones & & Valor del cliente & Gestión comercial \\
\hline $\begin{array}{llr}\text { Valor del } \\
\text { cliente }\end{array}$ & Correlación de Pearson & 1 & $0.875^{\star *}$ \\
& Sig. (bilateral) & & 0.000 \\
& $\mathrm{~N}$ & 147 & 147 \\
Gestión & Correlación de Pearson & $0.875^{\star *}$ & 1 \\
comercial & Sig. (bilateral) & 0.000 & 147 \\
& $\mathrm{~N}$ & 147 & \\
& & &
\end{tabular}

Observamos en la tabla que el indicador valor del cliente permite la mejora de la gestión comercial, ello se puede comprobar porque en la tabla se observa que el valor resultante de 0,718 es significativo, indicando una correlación alta (de 0,70 a 0,90) El resultado es corroborado mediante la prueba de significación bilateral de 0,000 menor a la probabilidad de 0,01.

Este es el resultado más significativo en la dimensión métrica del cliente.

\section{Métricas del supermercado}

Rotación de inventarios

Tabla 30 Correlación entre rotación de inventarios y gestión comercial

\begin{tabular}{llrr}
\hline Correlaciones & \multicolumn{1}{c}{$\begin{array}{c}\text { Rotación de } \\
\text { inventarios }\end{array}$} & Gestión comercial \\
\hline $\begin{array}{l}\text { Rotación de } \\
\text { inventarios }\end{array}$ & Correlación de Pearson & 1 & $0.884^{* *}$ \\
& Sig. (bilateral) & 147 & 0.000 \\
& $\mathrm{~N}$ & $0.884^{* *}$ & 147 \\
Gestión & Correlación de Pearson & 0.000 & 1 \\
comercial & Sig. (bilateral) & 147 & 147 \\
& $\mathrm{~N}$ & &
\end{tabular}


Observamos en la tabla que el indicador rotación de inventarios permite la mejora de la gestión comercial, ello se puede comprobar porque en la tabla se observa que el valor resultante de 0,884 es significativo, indicando una correlación alta (de 0,70 a 0,90) El resultado es corroborado mediante la prueba de significación bilateral de 0,000 menor a la probabilidad de 0,01.

Este indicador sería el más significativo en cuanto a la dimensión métrica del supermercado o negocio.

\section{Ciclo operativo}

Tabla 31 Correlación entre ciclo operativo y gestión comercial

\begin{tabular}{llrr}
\hline Correlaciones & Ciclo operativo & Gestión comercial \\
\hline $\begin{array}{l}\text { Ciclo } \\
\text { operativo }\end{array}$ & Correlación de Pearson & 1 & $0.802^{* *}$ \\
& Sig. (bilateral) & & 0.000 \\
& $\mathrm{~N}$ & 147 & 147 \\
Gestión & Correlación de Pearson & $0.802^{* *}$ & 1 \\
comercial & Sig. (bilateral) & 0.000 & 147 \\
& $\mathrm{~N}$ & 147 &
\end{tabular}

Según los resultados obtenidos mediante la correlación producto momento de Pearson encontramos que el indicador ciclo operativo permite la mejora de la gestión comercial, ello se puede comprobar porque en la tabla se observa que el valor resultante de 0,884 es significativo, indicando una correlación alta (de 0,70 a 0,90) El resultado es corroborado mediante la prueba de significación bilateral de 0,000 menor a la probabilidad de 0,01.

Ciclo de conversión de efectivo

Tabla 32 Correlación entre ciclo de conversión de efectivo y gestión comercial

\begin{tabular}{|c|c|c|c|}
\hline Correlaciones & & $\begin{array}{l}\text { Ciclo de } \\
\text { conversión de } \\
\text { efectivo }\end{array}$ & Gestión comercial \\
\hline \multirow{2}{*}{$\begin{array}{l}\text { Ciclo de } \\
\text { conversión de }\end{array}$} & Correlación de Pearson & & $0.802^{* *}$ \\
\hline & Sig. (bilateral) & & 0.000 \\
\hline
\end{tabular}




\begin{tabular}{llrr}
\hline efectivo & N & 147 & 147 \\
Gestión & Correlación de Pearson & $0.802^{* *}$ & 1 \\
comercial & Sig. (bilateral) & 0.000 & 147 \\
& $\mathrm{~N}$ & 147 & 14 \\
\hline
\end{tabular}

** La correlación es significativa al nivel 0,01 (bilateral).

Observamos en la tabla que el indicador ciclo de conversión de efectivo permite la mejora de la gestión comercial, ello se puede comprobar porque en la tabla se observa que el valor resultante de 0,857 es significativo, indicando una correlación alta (de 0,70 a 0,90) El resultado es corroborado mediante la prueba de significación bilateral de 0,000 menor a la probabilidad de 0,01 .

Análisis e Interpretación de los resultados de las métricas no financieras de los principales supermercados del Perú:

Cuadro 5 Análisis de métricas no financieras, Cencosud

\begin{tabular}{|c|c|c|c|c|c|}
\hline CENCOSUD & 2009 & 2010 & 2011 & 2012 & 2013 \\
\hline ROI comercial & $71 \%$ & $62 \%$ & $65 \%$ & $53 \%$ & $54 \%$ \\
\hline \multicolumn{6}{|l|}{ Métricas del mercado } \\
\hline Cuota del mercado (en ingresos) & $54 \%$ & $52 \%$ & $47 \%$ & $25 \%$ & $24 \%$ \\
\hline Penetración del mercado & $45 \%$ & $43 \%$ & $39 \%$ & $36 \%$ & $36 \%$ \\
\hline \multicolumn{6}{|l|}{ Métricas del cliente } \\
\hline Rentabilidad del cliente & $71 \%$ & $62 \%$ & $65 \%$ & $53 \%$ & $54 \%$ \\
\hline Valor del cliente CLTV & $S / .4,150$ & S/. 4,298 & S/. 4,557 & S/. 2,728 & S/. 2,715 \\
\hline $\mathrm{N}^{\circ}$ de cliente de Tottus & 5,020 & 4,997 & 5,285 & 5,242 & 5,780 \\
\hline Ticket promedio Tottus & S/. 44 & S/. 46 & $\mathrm{~S} / .49$ & S/. 52 & S/. 54 \\
\hline \multicolumn{6}{|l|}{ Métricas del supermercado } \\
\hline Rotación (en veces) & 16 & 15 & 16 & 13 & 27 \\
\hline Ciclo operativo (en días) & 26 & 28 & 27 & 23 & 80 \\
\hline $\begin{array}{l}\text { Ciclo de conversión en efectivo } \\
\text { (en días) }\end{array}$ & -60 & -61 & -60 & 0 & 0 \\
\hline
\end{tabular}

Fuente: Elaboración propia en base a Cencosud 2009, 2010, 2011, 2012, 2013. 
En el cuadro 5 se muestran los resultados de las métricas no financieras obtenidas para los supermercados Wong y Metro (Cencosud). Las métricas no financieras con mayor importancia por los retailers y con mayor correlación: penetración de mercado, rotación de inventarios y valor del cliente se analizan a continuación:

La penetración de mercado ha venido disminuyendo en los últimos cinco años, producto de la competencia y el reordenamiento financiero, luego de la adquisición del grupo supermercados Wong por parte de la empresa Cencosud en diciembre de 2007.

La rotación de inventarios o existencias se ha incrementado en el último año, en correlación al valor del cliente entre otros factores, y además por concentrar un mayor stock en los supermercados en provincias.

Respecto a la métrica valor del cliente, este ha venido perdiendo valor básicamente por las estrategias de marketing de la competencia, ofreciendo gran cantidad de ofertas y promociones, que inclinan la decisión de compra de los clientes.

El ciclo de conversión de efectivo es negativo porque la empresa cobra antes de lo que paga.

Cuadro 6 Análisis métricas no financieras, Supermercados Peruanos

\begin{tabular}{|c|c|c|c|c|c|}
\hline Supermercados Peruanos & 2009 & 2010 & 2011 & 2012 & 2013 \\
\hline ROI comercial & $34 \%$ & $39 \%$ & $33 \%$ & $32 \%$ & $27 \%$ \\
\hline \multicolumn{6}{|l|}{ Métricas del mercado } \\
\hline Cuota del mercado (en ingresos) & $37 \%$ & $39 \%$ & $36 \%$ & $34 \%$ & $31 \%$ \\
\hline Penetración del mercado & $31 \%$ & $32 \%$ & $35 \%$ & $33 \%$ & $33 \%$ \\
\hline \multicolumn{6}{|l|}{ Métricas del cliente } \\
\hline Rentabilidad del cliente & $34 \%$ & $39 \%$ & $33 \%$ & $32 \%$ & $27 \%$ \\
\hline Valor del cliente CLTV & $S / .3,578$ & $S / .3,880$ & S/. 3,204 & S/. 3,334 & $S / .3,211$ \\
\hline $\mathrm{N}^{\circ}$ de cliente de Tottus & 3,435 & 3,645 & 4,815 & 4,805 & 5,331 \\
\hline Ticket promedio Tottus & $\mathrm{S} / .38$ & $\mathrm{~S} / .40$ & $\mathrm{~S} / .41$ & $S / .43$ & S/. 46 \\
\hline \multicolumn{6}{|l|}{ Métricas del supermercado } \\
\hline Rotación (en veces) & 10 & 9 & 9 & 9 & 9 \\
\hline Ciclo operativo (en días) & 40 & 44 & 48 & 49 & 48 \\
\hline $\begin{array}{l}\text { Ciclo de conversión en efectivo } \\
\text { (en días) }\end{array}$ & -52 & -47 & -45 & -44 & -26 \\
\hline
\end{tabular}


Fuente: Elaboración propia en base a Supermercados Peruanos, 2009, 2010, 2011, 2012, 2013.

En el cuadro 6 se muestran los resultados de las métricas no financieras obtenidas para los supermercados Plaza Vea (Supermercados Peruanos). Las métricas no financieras con mayor importancia por los retailers y con mayor correlación: penetración de mercado, rotación de inventarios y valor del cliente se analizan a continuación:

La penetración de mercado se ha mantenido en los últimos cinco años, con una ligera baja en los dos últimos años, producto de estrategias de marketing defensivas, frente a la competencia, principalmente Tottus.

La rotación de inventarios o existencias se ha mantenido casi constante, debido entre otros factores a una adecuada política de inventarios manejada por el sistema de planificación de recursos empresariales, también llamado ERP (enterprise resources planning).

Respecto a la métrica valor del cliente, se ha mantenido constante debido a la alta fidelidad del cliente en el tiempo y básicamente por ser el supermercado con mayor crecimiento en número de locales en el Perú.

El ciclo de conversión de efectivo es negativo porque la empresa cobra antes de lo que paga.

\begin{tabular}{|c|c|c|c|c|c|}
\hline Tottus & 2009 & 2010 & 2011 & 2012 & 2013 \\
\hline ROI comercial & $34 \%$ & $59 \%$ & $45 \%$ & $53 \%$ & $54 \%$ \\
\hline \multicolumn{6}{|l|}{ Métricas del mercado } \\
\hline Cuota del mercado (en ingresos) & $21 \%$ & $24 \%$ & $25 \%$ & $25 \%$ & $24 \%$ \\
\hline Penetración del mercado & $25 \%$ & $25 \%$ & $26 \%$ & $30 \%$ & $31 \%$ \\
\hline \multicolumn{6}{|l|}{ Métricas del cliente } \\
\hline Rentabilidad del cliente & $34 \%$ & $59 \%$ & $45 \%$ & $53 \%$ & $54 \%$ \\
\hline Valor del cliente CLTV & S/. 1,748 & $\mathrm{S} / .2,135$ & $S / .2,406$ & S/. 2,215 & $S / .2,259$ \\
\hline $\mathrm{N}^{\circ}$ de cliente de Tottus & 2,780 & 2,906 & 3,588 & 4,344 & 4,889 \\
\hline Ticket promedio Tottus & S/. 26 & S/. 29 & S/. 33 & $\mathrm{~S} / .35$ & $\mathrm{~S} / .38$ \\
\hline \multicolumn{6}{|l|}{ Métricas del supermercado } \\
\hline Rotación (en veces) & 12 & 10 & 12 & 12 & 11 \\
\hline Ciclo operativo (en días) & 33 & 47 & 28 & 30 & 32 \\
\hline
\end{tabular}




$\begin{array}{llllll}\text { Ciclo de conversión en efectivo } & -13 & 2 & -8 & -8 & -5\end{array}$
(en días)

Fuente: Elaboración propia en base a Tottus, 2009, 2010, 2011, 2012, 2013.

En el cuadro 7 se muestran los resultados de las métricas no financieras obtenidas para los supermercados Tottus (Falabella). Las métricas no financieras con mayor importancia por los retailers y con mayor correlación: penetración de mercado, rotación de inventarios y valor del cliente se analizan a continuación:

La penetración de mercado se ha venido incrementando en los últimos cinco años, producto de las estrategias de marketing, concentrada básicamente en las estrategias de promoción, la agresiva estrategias de ofertas y promociones y a su gran incursión en provincias.

La rotación de inventarios o existencias se ha mantenido constante, dada las adecuadas políticas de inventarios y a la adquisición de un sistema de información y comunicación centralizada y automatizada como el ERP (enterprise resources planning).

Respecto a la métrica valor del cliente, este ha venido ganando valor básicamente por las estrategias de marketing, la gran cantidad de ofertas y promociones y la penetración en provincias, que inclinan la decisión de compra de los clientes.

El ciclo de conversión de efectivo es negativo porque la empresa cobra antes de lo que paga.

\section{Planteamiento del modelo}

Luego de la aplicación de la metodología propuesta, puedo presentar los principales hallazgos, tanto de las encuestas, como los de su análisis descriptivo, financiero y el análisis inferencial.

Evaluando las métricas no financieras, agrupadas en tres: métricas del mercado, métricas del cliente y métricas del supermercado o negocio, vemos que:

En primer lugar: Existe una mayor consideración a las métricas del cliente por parte de los 147 retailers de supermercados, siendo el valor del cliente la principal métrica considerada.

En segundo lugar: Se considera a las métricas del supermercado o del negocio, donde la principal métrica es la rotación de inventarios.

En tercer lugar: A consideración de los retailers, se encuentra las métricas del mercado, donde la principal métrica es la penetración del mercado. 
Estos resultados han sido corroborados en el análisis inferencial, donde la correlación de Pearson ha mostrado mayor significancia en las métricas antes mencionadas.

Por lo tanto, podemos indicar en la propuesta del modelo que es necesario e importante considerar al valor del cliente, la rotación de inventarios y la penetración del mercado como métricas que ofrecer ventajas en la rentabilidad del negocio de

\section{Conclusiones}

1) Las métricas no financieras que han mostrado mayor importancia para los 147 retailers encuestados, así como las que han obtenido mayor puntaje en la correlación de Pearson, son: valor del cliente (métrica del cliente), penetración de mercado (métrica del mercado) y rotación de inventarios (métrica del supermercado).

2) Se determinó que el análisis del retorno de la inversión de los supermercados en el Perú utilizando métricas no financieras mejora la gestión comercial.

3) Existe evidencia que el análisis del retorno de la inversión de los supermercados en el Perú utilizando métricas de mercado mejora la gestión comercial.

4) Existe evidencia que el análisis del retorno de la inversión de los supermercados en el Perú utilizando métricas de cliente mejora la gestión comercial.

5) Existe evidencia que el análisis del retorno de la inversión de los supermercados en el Perú utilizando métricas del supermercado mejora la gestión comercial.

6) El consenso obtenido del método Delphi nos lleva a concluir que la metodología propuesta es interesante para su aplicación y representa una contribución original al conocimiento en gestión comercial de supermercados en el Perú, pues aporta a la mejorará la gestión de la inversión comercial del sector.

\section{Reflexiones para el futuro}

1) Difundir a través de artículos periodísticos y conferencias las ventajas de utilizar las métricas no financieras en el sector de supermercados de la categoría económicos, respecto al retorno de la inversión comercial. 
2) Propiciar un modelo de gestión comercial de supermercados de la categoría económicos orientado a maximizar el valor del cliente, la penetración de mercado y la rotación de inventarios, factores que influyen en el retorno de la inversión comercial del sector, considerando para ello los factores o datos que contribuyen a la definición de cada métrica mencionada,

3) Realizar un estudio similar en otros formatos del sector retail como son las tiendas por departamento o los centros comerciales. 


\section{Referencias}

Berger, P. D. \& Nasr, N. I. (1998). Customer Lifetime Value: Mercadeo Models and Applications. Journal of Interactive Marketing, 12(1), 17-30. http://dx.doi.org/10.1002/(SICI)15206653(199824)12:1<17::AID-DIR3>3.0.CO;2-K.

Domínguez Doncel, A. \& Hermo Gutiérrez, S. (2007). Métricas del Marketing. Madrid: Editorial ESIC.

Domínguez Doncel, A. \& Muñoz Vera, G. (2010). Métricas del Marketing. Madrid: Editorial ESIC.

Equilibrium Clasificadora de Riesgo (2013). Análisis del Sector Retail: Supermercados.

Recuperado de http://www.equilibrium.com.pe/sectorialsuperjun13.pdf.

Bayón, T., Gutsche, J. \& Bauer, H. (2002). "Customer Equity Marketing: Touching the Intangible". European Management Journal, 20(3), 213-222. http://dx.doi.org/10.1016/S02632373(02)00037-3.

Hogan, J. E., Lemon, K. N. \& Rust, R. T. (2002). Customer Equity Management: Charting New Directions for the Future of Marketing. Journal of Service Research, 5(1), 4-12. http://dx.doi.org/10.1177/1094670502005001002.

Kotler, P. (2005). Dirección de mercadeo (10ma ed.) México D. F.: Pearson Education.

Lenskold, J. (2003). Marketing ROI: The Path to Campaign, Customer, and Corporate Profitability. New York: McGraw-Hill.

Linstone, H. A. \& Turoff, M. (1975). Delphi Method: Techniques and Applications. Boston: AddisonWesley.

Marketing Science Institute (2005). 2004-2006 research priorities - research priorities for the customer management community. Marketing Science Institute. Recuperado de http://www.msi.org/msi/rp050+cfm\#RPCMC.

Maximixe (2011). Informe de Estructura y Tendencias del Mercado de: Supermercados. Recuperado de http://www.maximixe.com/alertaeconomica/fichas/supermercados.pdf 
Rodríguez Herrera, V. A. (2013). Estimación del customer lifetime value a nivel de clientes, de un banco usando variables transaccionales y sociodemográficas (tesis de licenciatura). Recuperado del repositorio académico de la Universidad de Chile. http://www.repositorio.uchile.cl/handle/2250/113830.

Shaw, R. \& Stone, M. (1990). Database Marketing: Strategy and Implementation. New York: Wiley.

Stanton, W. J., Etzel, M. J. \& Walker, B. J. (1994). Fundamentals of Marketing. New York: McGraw Hill.

Valenzuela, L. \& Torres, E. (2008). Gestión empresarial orientada al valor del cliente como fuente de ventaja competitiva. Propuesta de un modelo explicativo. Estudios Gerenciales, 24(109), 65-86. http://dx.doi.org/10.1016/S0123-5923(08)70053-6. 


\section{Bibliografía}

Arellano, R. (2000). Los estilos de vida en el Perú. Cómo somos y pensamos los peruanos del siglo XXI. Lima: Consumidores y Mercados.

Arellano, R. (2007). “Haciendo crecer el mercado”. Anda News, 11(61), 54-56.

Audzeyeva, A., Summers, B. \& Schenk-Hoppe, K. R. (2012). Forecasting Customer Behavior in a Multi-Service Financial Organization: A Profitability Perspective. International Journal of Forecasting, 28(2), 507-518. http://dx.doi.org/10.1016/j.ijforecast.2011.05.005.

Berger, P., Bolton, R., Bowman, D. Kumar, V., Parasuraman, A \& Terry, C. (2002). Marketing Actions and the Value of Customer Assets: A Framework for Customer Asset Management. Journal of Service Research, 5(1), 39-54. http://dx.doi.org/10.1177/1094670502005001005.

Berger, P., Naras, E., Morris, G., Donald, L., Ross, R. \& Venkatesan, R. (2006). From Customer Lifetime Value to Shareholder Value. Theory, Empirical Evidence and Issues for Future Research. Journal of Service Research, 9(2): 156-167.

http://dx.doi.org/10.1177/1094670506293569.

Ellickson, P. B. (2013). Supermarkets as a Natural Oligopoly. Economic Inquiry, 51(2), 1142-1154. http://dx.doi.org/10.1111/i.1465-7295.2011.00432.x.

Gupta, S. \& Lehmann, D. R. (2003). Customer as Assets. Journal of Interactive Marketing 17(1), 924. http://dx.doi.org/10.1002/dir.10045.

Glady, N., Baesens, B. \& Croux, C. (2008). Modeling Churn Using Customer Lifetime Value. European Journal of Operational Research, 197(1), 402-411. http://dx.doi.org/10.1016/i.ejor.2008.06.027.

Hansotia, B. (2004). Company Activities for Managing Customer Equity. Journal of Database Marketing \& Customer Strategy Management, 11(4), 319-332.

http://dx.doi.org/10.1057/palgrave.dbm.3240231.

Hernández Sampieri, R. (2006). Metodología de la investigación (4ta ed.). México D. F.: McGrawHill. 
Kumar, V. (2010). A Customer Lifetime Value-Based Approach to Marketing in the Multichannel, Multimedia Retailing Environment. Journal of Interactive Marketing, 24(2), 71-85. http://dx.doi.org/10.1016/j.intmar.2010.02.008.

Lambin, J. J. (1991). Marketing estratégico (2da ed.). Madrid: McGraw-Hill.

Levine, D. M., Krehbiel, T. C. \& Berenson, M. L. (2006). Estadística para administración (4ta ed.). México D. F.: McGraw-Hill.

Mahuad, K. (2005). Evolución de los formatos comerciales. Parte I. Anda News, 10(50), 40-42.

Pipoli de Azambúa, G. (2003). El mercadeo y sus aplicaciones a la realidad peruana. Lima: Universidad del Pacífico.

Regalado, O., Fuentes, C. Aguirre, G, García, N., Miu, R. \& Vallejo, R. (2009). Factores críticos de éxito en los centros comerciales de Lima Metropolitana y el Callao. Recuperado de http://www.esan.edu.pe/publicaciones/Descargue\%20el\%20documento\%20completo .pdf.

Thompson, A. \& Strickland, A. (1998). Administración estratégicas. México D. F.: McGraw-Hill.

Valenzuela, L. M., García de Madariaga, J. \& Blasco, M. F. (2007). Orientación al valor del cliente y las nuevas métricas de mercadeo. revisión y análisis. Panorama Socioeconómico, 25(34), 70-75.

Valenzuela Fernández, L. (2007). La gestión del valor de la cartera de clientes y su efecto en el valor global de la empresa: diseño de un modelo explicativo como una herramienta para la toma de decisiones estratégicas de marketing (tesis doctoral). Recuperado de e-prints Complutense.

Valenzuela, L., Torres, E., Hidalgo, P \& Farias, P. (2013). Salesperson CLV Orientation's Effect on Performance. Journal of Business Research, 67(4), 550-557. http://dx.doi.org/10.1016/i.jbusres.2013.11.012.

Varela-Ruiz, M., Díaz-Bravo, L. \& García-Durán, R. (2012). Descripción y usos del método Delphi. Revista Investigación en Educación Médica, 1(2), 90-95.

Webster, A. L. (2005). Estadística aplicada a los negocios y a la economía (3ra ed.). Bogotá: McGraw-Hill. 